\title{
Characterisation of fasted state gastric and intestinal fluids collected from children
}

Gopal Pawar'; Eleni Papadatou-Soulou'; Julie Mason¹; Rafeeq Muhammed², Alison Watson²; Catherine Cotter ${ }^{2}$; Mohamed Abou-Elwafa Abdallah ${ }^{3,4}$; Stuart Harrad ${ }^{3}$; Claire Mackie ${ }^{5}$; Tina Arien ${ }^{5}$; Sabine Inghelbrecht ${ }^{5}$ and Hannah Batchelor*16

1. School of Pharmacy, Institute of Clinical Sciences, College of Medical and Dental Sciences, University of Birmingham, Edgbaston, B15 2TT, United Kingdom

2. Birmingham Children's Hospital, Steelhouse Lane, Birmingham, B4 6NH, United Kingdom

3. School of Geography, Earth, and Environmental Sciences, University of Birmingham, Birmingham B15 2TT, United Kingdom

4. Department of Analytical Chemistry, Faculty of Pharmacy, Assiut University, 71526 Assiut, Egypt

5. Janssen Research and Development, Turnhoutseweg 34, 2340 Beerse, Belgium

6. Strathclyde Institute of Pharmacy and Biomedical Sciences, University of Strathclyde, 161 Cathedral Street, Glasgow G4 ORE, United Kingdom

*Corresponding author:

Professor Hannah Batchelor, Strathclyde Institute of Pharmacy and Biomedical Sciences, 161 Cathedral Street, Glasgow G4 ORE

Hannah.batchelor@strath.ac.uk 


\section{Abstract}

Fundamental knowledge about the composition of intestinal fluids in paediatric populations is currently unavailable. This study aimed to characterise gastric and intestinal fluid from paediatric populations.

Gastric and intestinal fluid samples were obtained during routine clinical endoscopy from paediatric patients at a large teaching hospital. These fluids were characterised to measure the $\mathrm{pH}$; buffer capacity; osmolality; bile acid concentration and composition.

A total of 55 children were recruited to the study aged from 11 months to 15 years of age where 53 gastric fluid samples and 40 intestinal fluid samples were obtained. $\mathrm{pH}$ values recorded ranged from pH 0.57 to 11.05 (median: 2.50) in gastric fluids and from 0.89 to 8.97 (median: 3.27 ) in intestinal fluids. The buffer capacity did not change significantly between gastric and intestinal fluids with median values of $12 \mathrm{mM} / \mathrm{L} / \Delta \mathrm{pH}$ for both fluids. Gastric fluid osmolality values ranged from 1 to 615 $\mathrm{mOsm} / \mathrm{kg}$, while intestinal fluid values ranged from 35 to $631 \mathrm{mOsm} / \mathrm{kg}$.

Gastric fluid bile acid concentrations ranged from 0.002 to $2.3 \mathrm{mM}$ with a median value of $0.017 \mathrm{mM}$ whilst intestinal fluid bile acid concentrations ranged from 0.0008 to $3.3 \mathrm{mM}$ with a median value of $0.178 \mathrm{mM}$. Glycocholate; taurocholic acid; glycochenodeoxycholate and taurochenodeoxycholate were the most commonly identified bile acids within paediatric intestinal fluids.

All compositional components were associated with large inter-individual variability. Further work is required to develop simulated paediatric media and to explore the impact of these media on drug solubility and dissolution.

Keywords: gastrointestinal fluid; paediatric; bile acid; buffer capacity; $\mathrm{pH}$; osmolality 


\section{Introduction}

Drug solubility within the gastrointestinal (GI) tract is key to oral biopharmaceutics parameters including calculation of the maximum absorbable dose $[1,2]$ and biopharmaceutics classification system [3]. Inadequate solubility can limit absorption of certain active pharmaceutical ingredients (APIs) so it is important to accurately measure solubility in Gl fluids. However, Gl fluid is a complex media known to exhibit high inter-individual variability. Critical to the prediction of the oral absorption of drugs in children is knowledge of the physical environment within the paediatric intestinal tract. Fundamental knowledge about the composition of intestinal fluids in neonates and children is currently unavailable.

There are several studies where GI fluids have been collected and characterised in the biopharmaceutics arena. The majority of studies have been conducted on adult populations in the fasted state [4-12] yet there are also studies exploring the fed state [13, 14]. Previous studies conducted in adults and children [15] where fasted fluid was collected and characterised are listed in Supplementary Table 1. Methodology associated with the measurement of GI fluid have varied and there has been recent work published to standardise methods of assessment [16].

The development of simulated adult intestinal fluids based on aspirated intestinal fluids has shown superiority in predicting in vivo performance compared to simple buffers [17]. Currently used simulated intestinal fluids: fasted state simulated intestinal fluid (FaSSIF) and fed state simulated intestinal fluid (FeSSIF) are based on adult data sets [18]. However, it is recognised that the GI environment in children may be different to that in adults [19]. There have been reports that the differences in volumes of fluid present may affect the classification of APIs in children according to the adult biopharmaceutics classification system [20-24].

A comprehensive review [25] on paediatric GI fluids and the component materials revealed several differences in paediatric fluids compared to adult data. The findings included a relatively higher gastric osmolality (of $253 \mathrm{mOsm} / \mathrm{L}$ in infants at 8 months) compared to values reported in adults, no reports of bile concentrations or buffer capacity from paediatric intestinal fluids were found in this review. Based on this review, recipes for paediatric fasted state simulated gastric and intestinal fluids were proposed for both neonates and infants, these reflected worse case scenarios rather than informed compositional content [25]. Subsequent to the Maharaj et al (2016) review [25], a study investigating the composition of gastric fluid in a paediatric population was published [15]. This gastric fluid study reported $\mathrm{pH}$ values ranging from 1.2-8.3 in neonates up to 20 days old (a similar $\mathrm{pH}$ range is observed for infants although details are not listed); 0.93-8.15 in children (2-12 years) and 1.24-6.96 in adolescents (12-18 years). The majority of the osmolality values measured in gastric fluids were between 200-350 mOsmKg ${ }^{-1}$ for neonates and infants, with lower mean values of $152 \pm 74 \mathrm{mOsm} \mathrm{Kg}^{-1}$ in children and $196 \pm 73 \mathrm{mOsm} \mathrm{Kg}^{-1}$ in adolescents. Bile salt concentrations in gastric fluids were also measured and large variability was shown: for neonates the concentration ranged from 0 to $5.6 \mathrm{mM}$ (mean 0.19mM); infants ranged from 0-1.6 mM (mean 0.24 mM); children 0-1.1 mM (mean 0.10 mM) and for adolescents ranged from 0-6.3 mM (mean $0.76 \mathrm{mM}$ ) [15].

Bile acids are chemically similar compounds based on a steroid nucleus, when these acids are conjugated to sodium they are termed bile salts and often the terms bile acid and bile salt are used interchangeably. Differences in the number and position of hydroxyl groups in relation to the steroid structure dictate the specific bile acid present. The structure informs the balance between 
hydrophobic and hydrophilic components within the bile acid which in turn affects how the bile interacts with other chemicals, including how this may affect the solubility of an API [26]. Thus knowledge of bile acid composition within the intestinal fluid is critical and has previously been shown to have very large effects on API solubility $[27,28]$. Primary bile acids, cholic acid (CA) and chenodeoxycholic acid (CDC) are produced by the liver and conjugated to the amino acids glycine or taurine [29].

Several studies have reported the bile acid concentration in adult human intestinal fluids, a review of this literature suggested an overall mean bile acid concentration in the fasted duodenum of $3.3 \mathrm{mM}$ and $3.0 \mathrm{mM}$ in the fasted jejunum [30]. With regard to bile acid composition, adult studies have shown discrepancies in the bile acids detected and all data shows large inter subject variability that could explain these differences $[9,12,31]$. There is limited data available on bile acids from paediatric populations. Studies reporting bile acid concentrations in the Gl fluids of children are listed in Table 1. One study [15] reported relative bile acid compositions of gastric fluid with slight differences found between neonate and infant populations to that of children and adolescents, further details are provided in Table 1.

Drug solubility in the intestine drives absorption for certain APIs and small changes in solubility can have large effects on the absorbed dose and therefore subsequent therapy. The composition of GI fluid, therefore, influences drug product performance and may differ between children and adults. In the paediatric population, knowledge of Gl fluid composition is essential to develop and build biorelevant physical and in silico models with the potential to minimise the burden of clinical trials in children. This study seeks to characterise gastric and intestinal fluid from paediatric populations to include reports on bile acid concentration and composition and to compare these fluids to data from adult populations as well as gastric data from paediatric populations [15]. 


\begin{tabular}{|c|c|c|c|c|c|}
\hline Reference & Population age & Fed/Fasted & Fluid & Bile acid/salt concentration & Bile acids present \\
\hline [32] & 8 healthy neonates (3-15 days) & $\begin{array}{l}4 \text { hours after } \\
\text { last meal }\end{array}$ & Duodenal & $\begin{array}{l}0.50-5.29 \mathrm{mM} \text { (fasting values) } \\
\text { Mean value }=2.09 \mathrm{mM}\end{array}$ & $\begin{array}{l}\text { Taurine and glycine conjugates of cholic and } \\
\text { CDC acids (TC; TCDC; GC; GCDC). } \\
\text { The total concentrations of cholic and CDC acids } \\
\text { combined during the test meal ranged from } \\
0.41 \text { to } 1.48 \mathrm{mM} \text {. } \\
\text { The ratio typically showed a greater } \\
\text { concentration of cholic acid compared to CDC } \\
\text { acid }\end{array}$ \\
\hline [33] & $\begin{array}{l}18 \text { healthy preterm neonates } \\
\text { ( } 32-39 \text { weeks) }\end{array}$ & $\begin{array}{l}2 \text { hours after } \\
\text { last feed }\end{array}$ & Duodenal & $\begin{array}{l}0.44-23.3 \mathrm{mM} \\
\text { Mean value }=6.32 \mathrm{mM}\end{array}$ & Not stated. \\
\hline [34] & $\begin{array}{l}34 \text { neonates/infants (birth-7 } \\
\text { months) }\end{array}$ & $\begin{array}{l}2 \text { hours after } \\
\text { last meal }\end{array}$ & Duodenal & $1.65 \pm 1.1 \mathrm{mM}$ & $\begin{array}{l}\text { Glycine/taurine conjugates } 0.09( \pm 0.03) \mathrm{mM} \\
\text { Trihydroxy/dihydroxy bile acids } 1.8( \pm 1.3) \mathrm{mM} \\
\text { TC acid } 0.78( \pm 0.36) \mathrm{mM} \\
\text { TCDC acid } 0.68( \pm 0.40) \mathrm{mM} \\
\text { TLC acid } 0.32( \pm 0.17) \mathrm{mM} \\
\mathrm{GC} \text { acid } 0.25( \pm 0.15) \mathrm{mM} \\
\text { GCDC acid } 0.55 \mathrm{mM} \text { (1 sample) }\end{array}$ \\
\hline [35] & $\begin{array}{l}20 \text { low birth weight neonates } \\
\text { (12-22 days) }\end{array}$ & $\begin{array}{l}3 \text { hours after } \\
\text { last meal }\end{array}$ & Duodenal & $3.2-6.9 \mathrm{mM}$ & $\begin{array}{l}\text { Glycine conjugates } 1.2-4.6 \mathrm{mM} \\
\text { Taurine conjugates } 0.9-2.3 \mathrm{mM}\end{array}$ \\
\hline [36] & $\begin{array}{l}36 \text { neonates ( } 34 \pm 2.6 \text { weeks) } \\
16 \text { infants/children ( } 25 \pm 21 \\
\text { months) }\end{array}$ & $\begin{array}{l}\text { Pre-prandial } \\
\text { sample }\end{array}$ & Duodenal & $\begin{array}{l}\sim 3-4 \mathrm{mM} \text { (neonates) } \\
\sim 5-7 \mathrm{mM} \text { (infants/children) } \\
\text { Data sets read from graph and } \\
\text { exact values not available }\end{array}$ & $\begin{array}{l}\text { GCDC formed } 11 \% \text { of total bile salts in neonates } \\
\text { TLC was detected in higher frequency in the } \\
\text { infant/children group compared to neonates }\end{array}$ \\
\hline
\end{tabular}




\begin{tabular}{|c|c|c|c|c|c|}
\hline [37] & $\begin{array}{l}66 \text { healthy preterm neonates } \\
\text { (33-36 weeks) }\end{array}$ & $\begin{array}{l}1-3 \text { hours } \\
\text { after last } \\
\text { feed }\end{array}$ & Duodenal & $\begin{array}{l}\text { Median value } 3.63 \mathrm{mM} \text { in formula } \\
\text { fed neonates } \\
\text { Median value } 7.56 \mathrm{mM} \text { in breast } \\
\text { fed neonates }\end{array}$ & High levels of 2-OH cholate bile acids; $\mathrm{CDC}$ \\
\hline [38] & $\begin{array}{l}42 \text { low birthweight } \\
\text { neonate/infants ( } 15-51 \text { days) }\end{array}$ & $\begin{array}{l}\text { Pre-prandial } \\
\text { sample }\end{array}$ & Duodenal & $4.60 \pm 2.51 \mathrm{mM}$ & No details on composition of bile acids \\
\hline [39] & $\begin{array}{l}41 \text { healthy preterm } \\
\text { neonates/infants (8-58 days) }\end{array}$ & $\begin{array}{l}\text { 3-4 hours } \\
\text { after last } \\
\text { meal }\end{array}$ & Duodenal & $\begin{array}{l}\text { 27-28 gestational weeks: } 4.25 \\
\pm 2.07 \mathrm{mM} \\
33-34 \text { gestational weeks: } 4.47 \\
\pm 2.10 \mathrm{mM}\end{array}$ & $\begin{array}{l}\text { Secondary bile acids were not detectable } \\
\text { Cholic acid; CDC acid; DC acid and LC acid were } \\
\text { present }\end{array}$ \\
\hline [15] & $\begin{array}{l}11 \text { neonates ( } 0-28 \text { days) } \\
3 \text { infants ( } 28 \text { days- } 2 \text { years) } \\
30 \text { children ( } 2-12 \text { years) } \\
10 \text { adolescents ( } 12-18 \text { years) }\end{array}$ & Pre-prandial & Gastric & $\begin{array}{l}0.0-5.60 \mathrm{mM} \\
0.0-1.61 \mathrm{mM} \\
0.0-1.11 \mathrm{mM} \\
0.0-6.28 \mathrm{mM}\end{array}$ & $\begin{array}{l}\text { In neonate and infant populations the relative } \\
\text { order } G C>T C>T C D C>G C D C \\
\text { In children and adolescents where the order } \\
\text { was } G C>G C D C>T C>T C D C>G D C>T D C> \\
\text { GUDC }\end{array}$ \\
\hline
\end{tabular}

Table 1. Summary of cohort details from studies reported where bile acid concentrations were measured in paediatric population. Glycocholic acid (GC); glycochenodeoxycholic acid (GCDC); glycodeoxycholic acid (GDC); glycoursodeoxycholic acid (GUDC); taurocholic acid (TC); taurochenodeoxycholic acid (TCDC); taurodeoxycholic acid (TDC); tauroursodeoxycholic acid (TUDC); taurolithocholic acid (TLC); deoxycholic acid (DC), lithocholic acid (LC), and ursodeoxycholic acid (UDC). 


\section{Materials and Methods}

\section{Source of intestinal fluid samples}

All samples were collected from patients at Birmingham Children's Hospital, a large teaching hospital that is part of Birmingham Women's and Children's Hospital NHS Foundation Trust, UK. Ethical approval was granted by South Birmingham NRES Committee (IRAS 251909). Gastric and intestinal fluid samples were collected from participants during routine clinical endoscopy. Clinical protocols requested that no fluid was ingested in the 90 minutes prior to the endoscopy procedure. Gastric samples were collected from the gastric antrum and intestinal samples from the duodenum. The samples were stored at $-80^{\circ} \mathrm{C}$ prior to characterisation. The participants were stratified by age into the following groups, based on the International Conference on Harmonization (ICH) E11 classifications: $<2$ years: new-born/ infant/ toddler (the term infant is used for this group for the remainder of this manuscript), 2-5 years: pre-school age children, 6-11 years: school age children, 12-16 years: adolescents.

\section{Chemicals}

Bile salt standards: Cholic acid (CA); Glycocholic acid (GC); glycochenodeoxycholic acid (GCDC); glycodeoxycholic acid (GDC); glycoursodeoxycholic acid (GUDC); taurocholic acid (TC); taurochenodeoxycholic acid (TCDC); taurodeoxycholic acid (TDC); tauroursodeoxycholic acid (TUDC); taurolithocholic acid (TLC); deoxycholic acid (DC), lithocholic acid (LC), and ursodeoxycholic acid (UDC) were purchased from either Sigma Aldrich (Gillingham, UK) or Acros Organics (Fisher Scientific, Loughborough, UK). Internal standards (IS) were specific isotope labelled standards of cholic acid-D4 (D4-CA) and deoxycholic acid-D4 (D4-DC), purchased from Sigma Aldrich. Further details of physchem properties, CAS number, \% purity and purchase details of all standards are provided in Table 2 in the supplementary information.

\section{Methodology for characterisation of fluid samples collected}

pH: A Hanna HI 2210 pH meter was used for all measurements, calibrated on the day of use. A narrow pH electrode (Hanna HI1331B) was used to enable measurement of the small volumes available.

Buffer Capacity ( $\mathrm{mmol} / \mathrm{L})$ : The buffer capacity was measured by titrating each sample with $0.1 \mathrm{M}$ $\mathrm{NaOH}$ under constant stirring whilst monitoring the $\mathrm{pH}$ to measure the volume required for a change in pH of 1 unit. A calibrated Hanna $\mathrm{HI} 2210$ pH meter was used for all measurements. Previous studies measured buffer capacity using both $\mathrm{NaOH}$ and $\mathrm{HCl}$, however due to the small sample volumes available, only titration against $\mathrm{HCl}$ was performed for all samples [16]. The buffering capacity $(\beta)$ was calculated using the following equation:

$$
\beta=\frac{\Delta A}{\Delta p H}
$$

Where $\Delta \mathrm{A}$ is the amount of acid added and $\Delta \mathrm{pH}$ is the change in $\mathrm{pH}$ induced by the acid added.

Osmolality (mOsm/ kg): Osmolality was measured using a freezing point Osmomat 3000 that was calibrated prior to use. $50 \mu \mathrm{l}$ of each fluid sample was placed into the appropriate sample vial using a 20-200 $\mu$ l Thermoscientific pipette and the osmolality value was recorded. 


\section{Quantification and identification of bile salts}

A LC-MS/MS method was used based on published literature [12]. Separation of 14 bile acids was achieved using a dual pump Shimadzu LC-20AB Prominence liquid chromatograph equipped with SIL$20 \mathrm{~A}$ autosampler, a DGU-20A3 vacuum degasser and an Ascentis Express $C_{18}$ column $(15 \mathrm{~cm} \times 4.6 \mathrm{~mm}$ I.D., $2.7 \mu \mathrm{m}$; Sigma Aldrich). A mobile phase program based on (A) 1:1 methanol/water and (B) methanol at a flow rate of $150 \mu \mathrm{L} / \mathrm{min}$ was applied for elution of target analytes. Both solvent's $\mathrm{pH}$ were adjusted to 9.0 with $0.1 \%$ ammonium hydroxide $(25 \%)$ and $10 \mathrm{mM} / \mathrm{L}$ ammonium acetate. The flow started at $50 \%$ B and increased to $100 \%$ over 4 minutes, held at $100 \%$ B for 5 minutes then reduced to $50 \% \mathrm{~B}$ at 12 minutes.

Mass spectrometric analysis was performed using a Sciex API 2000 triple quadrupole mass spectrometer operated in electrospray negative ionization mode. MS/MS detection operated in the multiple reaction monitoring (MRM) mode was used for quantitative determination based on compound-specific MRM transitions. Full details are provided in Table 3 of the supplementary material.

Sample preparation: A simple protein precipitation method was followed for extraction of all bile acids from gastric and duodenal fluids. An aliquot of 100-250 $\mu \mathrm{L}$ fluid sample was precipitated with $440 \mu \mathrm{L}$ of acetonitrile:methanol (1:2) solvent containing $10 \mu \mathrm{L}$ internal standard (IS) (1000 ng/mL) and mixed for $15 \mathrm{~s}$ on a Vortex Mixer (Fisherbrand, UK). This sample mixture was centrifuged at $14,000 \mathrm{rpm}$ at $10^{\circ} \mathrm{C}$ for $10 \mathrm{~min}$. Initially the samples were diluted 2 times and then 5, 10, 100, and 200 times depending on the concentrations of each bile salt in the fluid sample. From the diluted supernatant 5 $\mu \mathrm{L}$ was injected onto the LC-MS/MS system for analysis.

A simple protein precipitation extraction technique was sufficient to obtain the best recovery for both the bile acid analytes and internal standards. The results of the comparison of neat standards (methanol: water spiked with bile acids) versus surrogate-matrix extracted standards for all the bile acids and the mean recovery was found to between $95-98 \%$ at three concentrations $(5,100 \& 2000$ $\mathrm{ng} / \mathrm{ml}$ ). The recovery for internal standards at $1000 \mathrm{ng} / \mathrm{ml}$ was $>98 \%$ in all the recovery samples.

The analysis method was shown to be linear from $2-2000 \mathrm{ng} / \mathrm{mL}$ and was capable of accurately and precisely determining bile acid concentrations in GI fluid samples according to the FDA requirements for bioanalytical method validation. Total bile acid concentration in each sample was calculated as the sum of the concentrations of the individual bile acids.

\section{Description of Statistical Methods}

Previous work to characterise the gastric and intestinal fluids in adults reported means, medians and range values of $\mathrm{pH}$; buffering capacity; osmolality; viscosity and bile salt concentration [4]. This work aims to characterise the same parameters for paediatric populations and to explore whether the values obtained are statistically similar to those reported in previous studies in both adult and paediatric populations. The differences in mean values between the sub-sets of paediatric populations as well as existing data from adults were compared using ANOVA analysis (with Tukey's post-hoc) to determine any significant differences. Outliers were identified using SPSS, these are presented in figures but were excluded from further analysis (SPSS uses a step of 1.5 $\times$ IQR (Interquartile range) to identify outliers). 


\section{Results and Discussion}

\section{Patient demographics}

A total of 55 children were recruited to the study ranging in age from 11 months to 15 years old. A total of 53 gastric fluid samples were collected with 2 from infants; 10 from pre-school age children, 20 from school age children and 21 from adolescents. A total of 40 intestinal fluid samples were collected with 2 from neonates-infants; 7 from pre-school age children; 16 from school age children and 15 from adolescents. Demographic data for all participants is provided in Table 2.

\begin{tabular}{|c|c|c|c|c|c|c|c|c|}
\hline $\begin{array}{l}\text { Participant } \\
\text { ID code }\end{array}$ & Ethnicity & Age (y) & $\begin{array}{l}\text { Height } \\
\text { (cm) }\end{array}$ & $\begin{array}{l}\text { Weight } \\
\text { (Kg) }\end{array}$ & $\begin{array}{l}\text { Reason for the } \\
\text { endoscopy }\end{array}$ & $\begin{array}{l}\text { Final } \\
\text { diagnosis } \\
\text { following } \\
\text { endoscopy }\end{array}$ & $\begin{array}{l}\text { Gastric } \\
\text { fluid } \\
\text { sample }\end{array}$ & $\begin{array}{l}\text { Duodenal } \\
\text { fluid } \\
\text { sample }\end{array}$ \\
\hline UK001 & $\begin{array}{l}\text { White } \\
\text { British }\end{array}$ & 13 & 158.6 & 48.5 & $\begin{array}{l}\text { Bleeding per } \\
\text { rectum }\end{array}$ & $\begin{array}{l}\text { Colonic } \\
\text { polyp }\end{array}$ & Yes & \\
\hline UK002 & $\begin{array}{l}\text { Any other } \\
\text { ethnic } \\
\text { group, not } \\
\text { specified }\end{array}$ & 10 & 142 & 33.2 & Abdominal pain & Normal & Yes & Yes \\
\hline UK003 & $\begin{array}{l}\text { White- not } \\
\text { specified }\end{array}$ & 13 & 173 & 56.2 & $\begin{array}{l}\text { Diarrhoea }+ \\
\text { Anaemia }\end{array}$ & $\begin{array}{l}\text { Coeliac } \\
\text { Disease }\end{array}$ & Yes & \\
\hline UK004 & $\begin{array}{l}\text { Not } \\
\text { specified }\end{array}$ & 2 & 84.1 & 11.9 & Vomiting & $\begin{array}{l}\text { Eosinophilic } \\
\text { oesophagitis }\end{array}$ & Yes & \\
\hline UK005 & $\begin{array}{l}\text { Asian/Asian } \\
\text { British - } \\
\text { Indian } \\
\end{array}$ & 11 & 151 & 38 & Abdominal pain & Normal & Yes & Yes \\
\hline UK006 & $\begin{array}{l}\text { White } \\
\text { British }\end{array}$ & 8 & 134.9 & 44.3 & Vomiting & Normal & Yes & Yes \\
\hline UK007 & $\begin{array}{l}\text { White } \\
\text { British }\end{array}$ & 6 & 112.8 & 21 & Vomiting & Normal & Yes & Yes \\
\hline UK008 & $\begin{array}{l}\text { White- not } \\
\text { specified }\end{array}$ & 2 & 94.2 & 14.9 & Diarrhoea & Normal & Yes & \\
\hline UK010 & $\begin{array}{l}\text { White } \\
\text { British }\end{array}$ & 12 & 155.4 & 45.3 & $\begin{array}{l}\text { Abdominal pain } \\
+ \text { constipation }\end{array}$ & Normal & Yes & Yes \\
\hline UK011 & $\begin{array}{l}\text { Black/Black } \\
\text { British - any } \\
\text { other black } \\
\text { background }\end{array}$ & 14 & 166.6 & 57.4 & Abdominal pain & Normal & Yes & \\
\hline UK012 & $\begin{array}{l}\text { White } \\
\text { British }\end{array}$ & 15 & 154 & 40.7 & Abdominal pain & $\begin{array}{l}\text { Crohn's } \\
\text { Disease }\end{array}$ & Yes & \\
\hline UK013 & $\begin{array}{l}\text { Asian/Asian } \\
\text { British - } \\
\text { Pakistani }\end{array}$ & 11 & 147.5 & 66.6 & $\begin{array}{l}\text { History of } \\
\text { choking } \\
\text { episodes }\end{array}$ & Normal & Yes & Yes \\
\hline UK014 & $\begin{array}{l}\text { Mixed } \\
\text { White and } \\
\text { Black } \\
\text { Caribbean }\end{array}$ & 14 & 169.9 & 79.9 & Abdominal pain & Normal & Yes & Yes \\
\hline UK015 & $\begin{array}{l}\text { White } \\
\text { British }\end{array}$ & 14 & 171 & 62.8 & $\begin{array}{l}\text { Abdominal pain } \\
+ \text { Diarrhoea }\end{array}$ & Normal & Yes & \\
\hline UK017 & $\begin{array}{l}\text { White } \\
\text { British }\end{array}$ & 14 & 152.6 & 52.5 & Dyspepsia & Normal & Yes & Yes \\
\hline UK018 & $\begin{array}{l}\text { White } \\
\text { British }\end{array}$ & 12 & 169 & 60.9 & Abdominal pain & Normal & Yes & Yes \\
\hline
\end{tabular}




\begin{tabular}{|c|c|c|c|c|c|c|c|c|}
\hline UK019 & $\begin{array}{l}\text { Asian/Asian } \\
\text { British }\end{array}$ & 15 & 163.5 & 37.8 & $\begin{array}{l}\text { Abdominal pain, } \\
\text { diarrhoea }+ \\
\text { weight loss }\end{array}$ & $\begin{array}{l}\text { Crohn's } \\
\text { Disease }\end{array}$ & Yes & Yes \\
\hline UK020 & $\begin{array}{l}\text { Not } \\
\text { specified }\end{array}$ & 3 & 91.8 & 15.1 & $\begin{array}{l}\text { Asymptomatic } \\
\text { type } 1 \text { diabetic } \\
\text { patient, } \\
\text { screening for } \\
\text { Coeliac Disease }\end{array}$ & $\begin{array}{l}\text { Coeliac } \\
\text { Disease }\end{array}$ & Yes & \\
\hline UK021 & $\begin{array}{l}\text { Asian/Asian } \\
\text { British - } \\
\text { Indian }\end{array}$ & 3 & 94.9 & 14.3 & $\begin{array}{l}\text { Hypothyroidism- } \\
\text { routine } \\
\text { screening for } \\
\text { Coeliac Disease }\end{array}$ & $\begin{array}{l}\text { Coeliac } \\
\text { Disease }\end{array}$ & Yes & Yes \\
\hline UK022 & $\begin{array}{l}\text { Asian/Asian } \\
\text { British - } \\
\text { Pakistani }\end{array}$ & 11 & 139 & 22.5 & $\begin{array}{l}\text { Slow weight } \\
\text { gain }\end{array}$ & $\begin{array}{l}\text { Coeliac } \\
\text { Disease }\end{array}$ & Yes & Yes \\
\hline UK023 & $\begin{array}{l}\text { Not } \\
\text { specified }\end{array}$ & 15 & 177.1 & 64.2 & Abdominal pain & Normal & Yes & Yes \\
\hline UK024 & $\begin{array}{l}\text { White } \\
\text { British }\end{array}$ & 11 & 158 & 38.2 & Abdominal pain & Normal & Yes & Yes \\
\hline UK025 & $\begin{array}{l}\text { White } \\
\text { British }\end{array}$ & 12 & 162.9 & 52.2 & $\begin{array}{l}\text { Abdominal pain } \\
+ \text { weight loss }\end{array}$ & Normal & Yes & Yes \\
\hline UK026 & $\begin{array}{l}\text { Not } \\
\text { specified }\end{array}$ & 13 & 150.2 & 42.1 & Abdominal pain & Normal & Yes & Yes \\
\hline UK027 & $\begin{array}{l}\text { Asian/Asian } \\
\text { British - } \\
\text { Indian }\end{array}$ & 7 & 129 & 22.5 & $\begin{array}{l}\text { Difficulty in } \\
\text { swallowing }\end{array}$ & $\begin{array}{l}\text { Eosinophilic } \\
\text { oesophagitis }\end{array}$ & Yes & \\
\hline UK028 & $\begin{array}{l}\text { White } \\
\text { British }\end{array}$ & 12 & 153.7 & 47.1 & $\begin{array}{l}\text { Surveillance } \\
\text { endoscopy }\end{array}$ & $\begin{array}{l}\text { Eosinophilic } \\
\text { oesophagitis }\end{array}$ & Yes & \\
\hline UK029 & $\begin{array}{l}\text { White } \\
\text { British }\end{array}$ & 15 & 179.2 & 61.8 & Abdominal pain & Normal & Yes & Yes \\
\hline UK030 & $\begin{array}{l}\text { Asian/Asian } \\
\text { British - } \\
\text { Pakistani }\end{array}$ & 10 & 123 & 21.2 & $\begin{array}{l}\text { Protein-losing } \\
\text { Enteropathy }\end{array}$ & Normal & Yes & \\
\hline UK031 & $\begin{array}{l}\text { White } \\
\text { British }\end{array}$ & 9 & 136.6 & 25.9 & Abdominal pain & Normal & Yes & Yes \\
\hline UK032 & $\begin{array}{l}\text { Asian/Asian } \\
\text { British - } \\
\text { Pakistani }\end{array}$ & 1 & 77.5 & 8.5 & $\begin{array}{l}\text { Part of work up } \\
\text { for stem cell } \\
\text { transplant }\end{array}$ & Normal & Yes & Yes \\
\hline UK033 & $\begin{array}{l}\text { Asian/Asian } \\
\text { British - } \\
\text { Indian }\end{array}$ & 15 & 155.6 & 39.8 & $\begin{array}{l}\text { Inflammatory } \\
\text { bowel disease } \\
\text { surveillance }\end{array}$ & Normal & Yes & Yes \\
\hline UK034 & $\begin{array}{l}\text { White } \\
\text { British }\end{array}$ & 15 & 167.8 & 47.4 & $\begin{array}{l}\text { Slow weight } \\
\text { gain }\end{array}$ & Normal & Yes & Yes \\
\hline UK035 & $\begin{array}{l}\text { Asian/Asian } \\
\text { British - } \\
\text { Pakistani }\end{array}$ & 10 & 130.1 & 18.6 & $\begin{array}{l}\text { Abdominal pain, } \\
\text { slow weight gain } \\
+ \text { constipation }\end{array}$ & Normal & Yes & Yes \\
\hline UK036 & $\begin{array}{l}\text { White } \\
\text { British }\end{array}$ & 5 & 117.4 & 22.6 & $\begin{array}{l}\text { Suspected } \\
\text { Coeliac Disease }\end{array}$ & Normal & Yes & Yes \\
\hline UK037 & $\begin{array}{l}\text { Mixed } \\
\text { White and } \\
\text { Black } \\
\text { Caribbean }\end{array}$ & 6 & 131.8 & 35.9 & $\begin{array}{l}\text { History of } \\
\text { diarrhoea }\end{array}$ & Normal & Yes & Yes \\
\hline UK038 & $\begin{array}{l}\text { Asian/Asian } \\
\text { British - } \\
\text { Indian }\end{array}$ & 8 & 134 & 44.1 & $\begin{array}{l}\text { Surveillance of } \\
\text { Reflux } \\
\text { Oesophagitis }\end{array}$ & $\begin{array}{l}\text { Reflux } \\
\text { Oesophagitis }\end{array}$ & Yes & Yes \\
\hline UK039 & $\begin{array}{l}\text { White } \\
\text { British }\end{array}$ & 12 & 164 & 57.5 & $\begin{array}{l}\text { Surveillance of } \\
\text { Eosinophilic } \\
\text { Oesophagitis }\end{array}$ & $\begin{array}{l}\text { Helicobacter } \\
\text { gastritis. } \\
\text { Eosinophilic } \\
\text { oesophagitis }\end{array}$ & Yes & Yes \\
\hline UK040 & $\begin{array}{l}\text { Mixed } \\
\text { other }\end{array}$ & 12 & 161.9 & 41.8 & $\begin{array}{l}\text { Surveillance of } \\
\text { Duodenal ulcer }\end{array}$ & $\begin{array}{l}\text { Duodenal } \\
\text { ulcer }\end{array}$ & Yes & Yes \\
\hline
\end{tabular}




\begin{tabular}{|c|c|c|c|c|c|c|c|c|}
\hline UK041 & $\begin{array}{l}\text { White } \\
\text { British }\end{array}$ & 12 & 141.3 & 29.9 & $\begin{array}{l}\text { Surveillance of } \\
\text { Crohn's Disease }\end{array}$ & $\begin{array}{l}\text { Crohn's } \\
\text { Disease }\end{array}$ & Yes & Yes \\
\hline UK042 & $\begin{array}{l}\text { White } \\
\text { British }\end{array}$ & 3 & 99.7 & 14.4 & $\begin{array}{l}\text { History of blood } \\
\text { in vomit }\end{array}$ & Normal & Yes & Yes \\
\hline UK043 & $\begin{array}{l}\text { Asian/Asian } \\
\text { British - } \\
\text { Indian }\end{array}$ & 11 & 144.1 & 31.8 & $\begin{array}{l}\text { Suspected } \\
\text { Inflammatory } \\
\text { Bowel Disease }\end{array}$ & $\begin{array}{l}\text { Ulcerative } \\
\text { Colitis }\end{array}$ & Yes & Yes \\
\hline UK044 & $\begin{array}{l}\text { White } \\
\text { British }\end{array}$ & 8 & 119.8 & 21.9 & $\begin{array}{l}\text { Suspected } \\
\text { Coeliac Disease }\end{array}$ & $\begin{array}{l}\text { Coeliac } \\
\text { Disease }\end{array}$ & Yes & Yes \\
\hline UK045 & $\begin{array}{l}\text { White- not } \\
\text { specified }\end{array}$ & 14 & 184 & 57.6 & Abdominal pain & Normal & Yes & Yes \\
\hline UK046 & $\begin{array}{l}\text { White } \\
\text { British }\end{array}$ & 3 & 97.1 & 15.4 & $\begin{array}{l}\text { Complaints of } \\
\text { Diarrhoea }\end{array}$ & Normal & Yes & Yes \\
\hline UK047 & $\begin{array}{l}\text { White } \\
\text { British }\end{array}$ & 7 & 112.6 & 17.6 & $\begin{array}{l}\text { Surveillance of } \\
\text { Crohn's Disease }\end{array}$ & $\begin{array}{l}\text { Crohn's } \\
\text { Disease }\end{array}$ & Yes & Yes \\
\hline UK048 & $\begin{array}{l}\text { White } \\
\text { British }\end{array}$ & 6 & 115.2 & 19.9 & $\begin{array}{l}\text { History of } \\
\text { diarrhoea }\end{array}$ & Normal & Yes & Yes \\
\hline UK049 & $\begin{array}{l}\text { White } \\
\text { British }\end{array}$ & $\begin{array}{l}11 \\
\text { months }\end{array}$ & 65 & 7.4 & $\begin{array}{l}\text { Suspected } \\
\text { Coeliac Disease }\end{array}$ & $\begin{array}{l}\text { Coeliac } \\
\text { Disease }\end{array}$ & Yes & Yes \\
\hline UK050 & $\begin{array}{l}\text { White } \\
\text { British }\end{array}$ & 10 & 129.1 & 25.5 & $\begin{array}{l}\text { Suspected } \\
\text { Coeliac Disease }\end{array}$ & $\begin{array}{l}\text { Coeliac } \\
\text { Disease }\end{array}$ & Yes & Yes \\
\hline UK051 & $\begin{array}{l}\text { White } \\
\text { British }\end{array}$ & 10 & 133.6 & 28.9 & $\begin{array}{l}\text { Suspected } \\
\text { Coeliac Disease }\end{array}$ & Normal & Yes & Yes \\
\hline UK052 & $\begin{array}{l}\text { Asian/Asian } \\
\text { British }\end{array}$ & 6 & 129 & 24.1 & $\begin{array}{l}\text { Surveillance of } \\
\text { Ulcerative } \\
\text { Colitis }\end{array}$ & $\begin{array}{l}\text { Ulcerative } \\
\text { Colitis }\end{array}$ & Yes & Yes \\
\hline UK053 & $\begin{array}{l}\text { White- not } \\
\text { specified }\end{array}$ & 4 & 99.7 & 16.5 & $\begin{array}{l}\text { Suspected } \\
\text { chronic } \\
\text { diarrhoea }\end{array}$ & Constipation & Yes & Yes \\
\hline UK054 & $\begin{array}{l}\text { White } \\
\text { British }\end{array}$ & 2 & 88.3 & 14.1 & $\begin{array}{l}\text { Bloody } \\
\text { diarrhoea, } \\
\text { suspected } \\
\text { inflammatory } \\
\text { bowel disease }\end{array}$ & $\begin{array}{l}\text { Ulcerative } \\
\text { Colitis }\end{array}$ & Yes & Yes \\
\hline UK055 & $\begin{array}{l}\text { Asian/Asian } \\
\text { British - } \\
\text { Indian }\end{array}$ & 4 & 109.1 & 18.2 & $\begin{array}{l}\text { Abdominal pain, } \\
\text { suspected } \\
\text { coeliac disease }\end{array}$ & $\begin{array}{l}\text { Coeliac } \\
\text { Disease }\end{array}$ & Yes & Yes \\
\hline UK056 & $\begin{array}{l}\text { Asian/Asian } \\
\text { British - } \\
\text { Pakistani } \\
\end{array}$ & $\begin{array}{l}13 \\
\text { months }\end{array}$ & 82 & 8.6 & Not recorded & $\begin{array}{l}\text { Not } \\
\text { recorded }\end{array}$ & & Yes \\
\hline UK057 & $\begin{array}{l}\text { White } \\
\text { British }\end{array}$ & 2 & 83 & 10.8 & $\begin{array}{l}\text { Chronic } \\
\text { diarrhoea, } \\
\text { suspected } \\
\text { Coeliac disease }\end{array}$ & $\begin{array}{l}\text { Coeliac } \\
\text { Disease }\end{array}$ & Yes & Yes \\
\hline UK058 & $\begin{array}{l}\text { White } \\
\text { British }\end{array}$ & 5 & 110.7 & 18.4 & $\begin{array}{l}\text { Chronic } \\
\text { diarrhoea }\end{array}$ & Normal & Yes & Yes \\
\hline UK059 & $\begin{array}{l}\text { White } \\
\text { British }\end{array}$ & 2 & 91.8 & 13.8 & Vomiting & $\begin{array}{l}\text { Gastro } \\
\text { Oesophageal } \\
\text { Reflux } \\
\text { disease }\end{array}$ & Yes & Yes \\
\hline UK060 & $\begin{array}{l}\text { White } \\
\text { British }\end{array}$ & 5 & 116.9 & 20.75 & Dyspepsia & $\begin{array}{l}\text { Functional } \\
\text { dyspepsia }\end{array}$ & Yes & Yes \\
\hline UK061 & $\begin{array}{l}\text { Asian/Asian } \\
\text { British - } \\
\text { Pakistani }\end{array}$ & 3 & 100.5 & 14.5 & $\begin{array}{l}\text { Bloody } \\
\text { diarrhoea }\end{array}$ & $\begin{array}{l}\text { Ulcerative } \\
\text { Colitis }\end{array}$ & Yes & \\
\hline UK062 & $\begin{array}{l}\text { White } \\
\text { British }\end{array}$ & 4 & 109 & 19.3 & Not recorded & $\begin{array}{l}\text { Not } \\
\text { recorded }\end{array}$ & Yes & Yes \\
\hline
\end{tabular}

Table 2. Demographics of the participants included in the fluid characterisation study 
Analysis (visual review of data plus statistical analysis where sample sizes permitted) was undertaken to explore the impact of ethnicity and final diagnosis following endoscopy on all characterisation parameters and no significant correlations were identified. All data was stratified based on age for subsequent data presentation.

\section{pH of gastric and intestinal fluids}

The $\mathrm{pH}$ values measured are shown stratified by age in Figure 1 from 53 participants' gastric fluid and 41 participants' intestinal fluid.

(a)

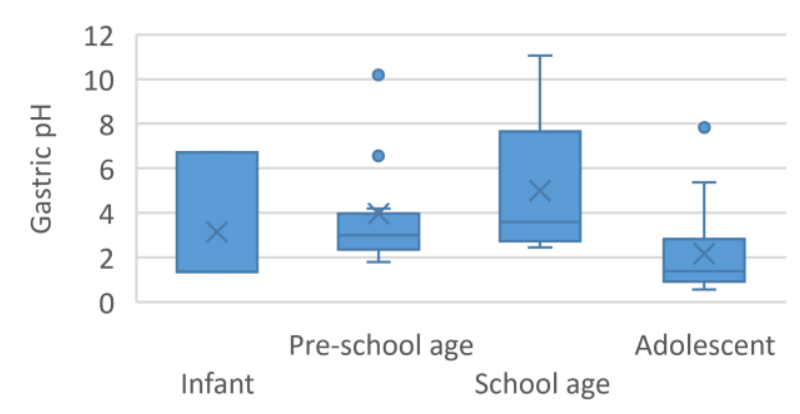

Age category (b)

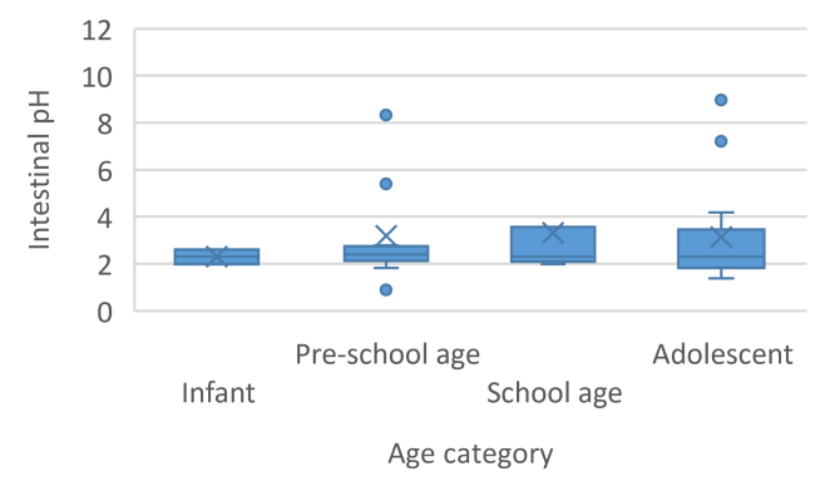

Figure 1. Box and whisker plots showing the $\mathrm{pH}$ from (a) gastric and (b) intestinal samples stratified by age group. Boxplots show mean as the $\mathrm{x}$; median as the horizontal line; box as the $1 \mathrm{Q}$ and $3 \mathrm{Q}$ and the whiskers are the range excluding outliers; outliers are shown as circle datapoints.

As shown in Figure 1 there is a lot of variability in the data where the $\mathrm{pH}$ values recorded ranged from pH 0.57 to 11.05 (mean: 3.51) in gastric fluids and from 0.89 to 8.97 (mean: 3.15 ) in intestinal fluids. Statistically significant differences in $\mathrm{pH}$ values were only identified for gastric samples between the school age and adolescent aged sub-groups $(\mathrm{p}=0.013)$. Previous reports on $\mathrm{pH}$ measurements of aspirated fluids from both paediatric and adult populations have also reported large variability $[5,15]$. The median, mean and standard deviation are shown by age in Table 3.

Some of the very high $\mathrm{pH}$ values measured may be an artefact of the measuring technique where the $\mathrm{pH}$ probe was not measuring a homogenous aqueous liquid and there was some form of physical interference by the other components, for example, solid materials or oils within the aspirated fluid that prevented an accurate measurement. Previous data sets have reported higher than expected $\mathrm{pH}$ values within gastric fluids in paediatric populations [15]. However, outliers, which included those with a gastric $\mathrm{pH}>10$, were excluded from subsequent analysis (as described in the methods section).

\begin{tabular}{|c|c|c|c|c|}
\hline & Infants & $\begin{array}{l}\text { Pre-school } \\
\text { Children }\end{array}$ & $\begin{array}{l}\text { School age } \\
\text { children }\end{array}$ & Adolescents \\
\hline 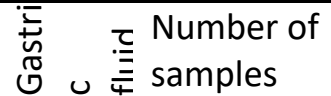 & 3 & 13 & 12 & 18 \\
\hline
\end{tabular}




\begin{tabular}{|c|c|c|c|c|c|}
\hline & Median & 1.36 & 2.77 & 3.24 & 1.31 \\
\hline & Mean & 3.14 & 2.78 & 4.06 & 1.67 \\
\hline & $\begin{array}{l}\text { Standard } \\
\text { deviation }\end{array}$ & 3.09 & 0.61 & 2.05 & 1.15 \\
\hline \multirow{4}{*}{ 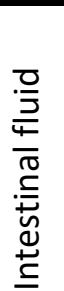 } & $\begin{array}{l}\text { Number of } \\
\text { samples }\end{array}$ & 2 & 13 & 6 & 13 \\
\hline & Median & - & 2.36 & 2.29 & 2.26 \\
\hline & Mean & 2.30 & 2.23 & 2.49 & 2.38 \\
\hline & $\begin{array}{l}\text { Standard } \\
\text { deviation }\end{array}$ & - & 0.48 & 0.58 & 0.81 \\
\hline
\end{tabular}

Table 3. Median, mean and standard deviation of the $\mathrm{pH}$ of gastric and intestinal samples. Note that outliers were excluded from this analysis.

The gastric $\mathrm{pH}$ was higher this study than previously reported in adults and paediatric studies. The samples in the current study were taken during endoscopy where the children were under a general anaesthetic. Under anaesthetic there may be relaxation of the pyloric sphincter and thus mixing of gastric and intestinal fluids which can affect the $\mathrm{pH}$. Depression of protective reflexes during anaesthesia and loss of consciousness has been reported to predispose patients to, duodenal-gastric reflux, specifically those with abdominal pain [40]. This factor may explain the increased mixing between intestinal and gastric fluids within this patient population. It is worth noting that previous studies characterising paediatric gastric fluids obtained the fluid samples via indwelling nasogastric tubes rather than under anaesthetic [15].

The mean values for gastric $\mathrm{pH}$ in school age children and adolescents matches previously reported values $\mathrm{pH}<3$ in the literature $[15,41,42]$. Although previous studies $[41,42]$ have reported that children have gastric $\mathrm{pH}$ values of less than 3; Van den Abeele et al reported that $3 / 35$ gastric samples from children were greater than $\mathrm{pH} 4$ whereas in our study $11 / 49$ were higher than $\mathrm{pH} 4$ thus there was an increased frequency of higher $\mathrm{pH}$ values in our study compared to previous data. As stated previously this difference may be linked to the methodology associated with collection of fluids.

Previous literature (shown in Table 4) reported mean or median intestinal fluid $\mathrm{pH}$ values in children to range from 6-8 which is higher than the values identified in this study. Our values are also lower than reported values from a review of studies conducted in adults where mean values ranged from 5.7-7.5 [30]. These lower than anticipated values are again likely to be a result of the mixing of gastric and duodenal fluids due to the sampling technique where the participants were anaesthetised prior to the endoscopy. The samples were frozen prior to measurement of $\mathrm{pH}$ as immediate measurement was not possible. Previous studies have reported that $\mathrm{pH}$ values can drift over time when samples are exposed to laboratory conditions due to transformation of bicarbonates to carbon dioxide which may also contribute to the higher than expected values for the gastric and lower for the intestinal fluids [43].

\begin{tabular}{lll}
\hline Reference & Sample details & Intestinal $\mathrm{pH}$ value recorded \\
\hline$[44]$ & In situ pH measurements from 34 & Mean pH of 6.6 \\
& children $<4$ years old & Range 5.6-7.3 \\
\hline
\end{tabular}




\begin{tabular}{|c|c|c|}
\hline [45] & $\begin{array}{l}\text { Intestinal aspirates from } 35 \text { children ( } 8 \\
\text { days }-19 \text { years) } \\
\text { In a subset of fasted children }(n=25)\end{array}$ & $\begin{array}{l}\text { Mean } \mathrm{pH} \text { of } 6.8 \\
\text { Range } 4.5-12.0 \\
\text { Mean } \mathrm{pH} \text { of } 7.0 \\
\text { Range } 5.5-7.6\end{array}$ \\
\hline [46] & $\begin{array}{l}\text { Intestinal aspirates from } 7 \text { children (0-14 } \\
\text { years) }\end{array}$ & $\begin{array}{l}\text { Mean } \mathrm{pH} 7.5 \\
\text { Range } 5.9-8.2\end{array}$ \\
\hline [47] & Intestinal aspirates from 2 infants & $\begin{array}{l}\text { Mean } \mathrm{pH} 7.8 \\
\text { Range } 7.39-8.20\end{array}$ \\
\hline$[41]$ & $\begin{array}{l}\text { In situ } \mathrm{pH} \text { measurements from } 12 \\
\text { children aged 8-14 years }\end{array}$ & Mean value of 6.4 (duodenum) \\
\hline
\end{tabular}

Table 4. Reported intestinal pH values from studies conducted in children

\section{Buffer Capacity}

Buffer capacity measurements were obtained from 52 gastric and 38 intestinal fluids and the results are shown in Figure 2. The measured buffer capacity $(\mathrm{mmol} / \mathrm{L} / \Delta \mathrm{pH})$ ranged from 0-189 and 5-150 for gastric and intestinal fluids respectively. There was no effect of age upon buffer capacity, although higher gastric buffer capacity values were recorded for older children.

(a)

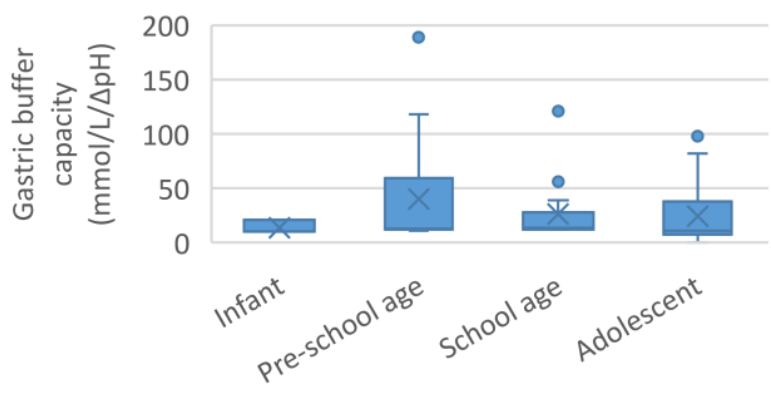

Age category (b)

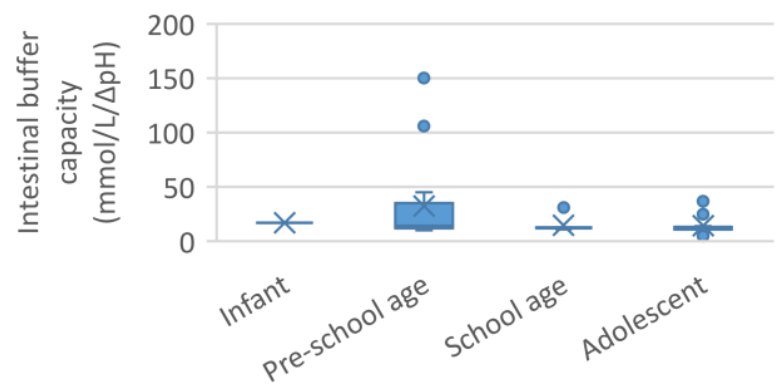

Age category

Figure 2. Box and whisker plots showing the buffer capacity $(\mathrm{mmol} / \mathrm{L} / \Delta \mathrm{pH})$ for (a) gastric and (b) intestinal samples by age group. Boxplots show mean as the $x$; median as the horizontal line; box as the $1 Q$ and $3 Q$ and the whiskers are the range excluding outliers; outliers are shown as circles.

Following removal of outliers the median, mean and standard deviation were calculated and are presented in Table 5 . No statistically significant differences were found in buffer capacity based on age sub groups.

\begin{tabular}{|lccc|}
\hline Infants & $\begin{array}{c}\text { Pre-school } \\
\text { Children }\end{array}$ & $\begin{array}{c}\text { School age } \\
\text { children }\end{array}$ & Adolescents \\
\hline
\end{tabular}




\begin{tabular}{|c|c|c|c|c|c|}
\hline \multirow{4}{*}{ 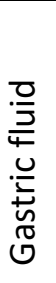 } & $\begin{array}{l}\text { Number of } \\
\text { samples }\end{array}$ & 3 & 16 & 14 & 15 \\
\hline & Median & 10.00 & 13.00 & 13.50 & 10.00 \\
\hline & Mean & 13.67 & 39.94 & 26.29 & 11.71 \\
\hline & $\begin{array}{l}\text { Standard } \\
\text { deviation }\end{array}$ & 6.35 & 52.61 & 30.19 & 11.12 \\
\hline \multirow{4}{*}{ 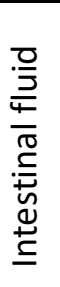 } & $\begin{array}{l}\text { Number of } \\
\text { samples }\end{array}$ & 1 & 14 & 5 & 11 \\
\hline & Median & 17.00 & 13.00 & 12.00 & 12.00 \\
\hline & Mean & 17.00 & 18.57 & 12.20 & 12.09 \\
\hline & $\begin{array}{l}\text { Standard } \\
\text { deviation }\end{array}$ & - & 10.86 & 0.45 & 0.94 \\
\hline
\end{tabular}

Table 5. Median, mean and standard deviation of the buffer capacity of gastric and intestinal samples. Note that outliers were excluded from this analysis.

The buffer capacity did not change significantly between gastric and intestinal fluids, this could be attributed to the fact that pylorus sphincter is relaxed due to anaesthesia causing the gastric and upper intestinal contents to be mixed.

The buffer capacity of intestinal fluids is of interest as changes in the $\mathrm{pH}$ can have dramatic effects on API solubility, thus low buffer capacity can indicate a risk of a change in the $\mathrm{pH}$ due to dissolution of an API or excipients. Previous literature has reported buffer capacity values for fasted adult human intestinal fluids ranging from 2.5-13 mM/L/ $\mathrm{pH}[30,43]$. Higher buffer capacity has been reported in the fed state and also following ingestion of water [43]. No data has been identified that reports the buffer capacity of paediatric fluids. The existing proposed paediatric simulated intestinal fluids have a buffer capacity of $10 \mathrm{mM} / \mathrm{L} / \Delta \mathrm{pH}$ [25] which matches the median values from our data as well as (the buffer capacity of adult FaSSIF which is $12 \mathrm{mM} / \mathrm{L} / \Delta \mathrm{pH}$ ) [48].

\section{Osmolality}

Osmolality measurements were obtained from 52 gastric and 41 intestinal fluids and the results are shown in Figure 3.

(a)

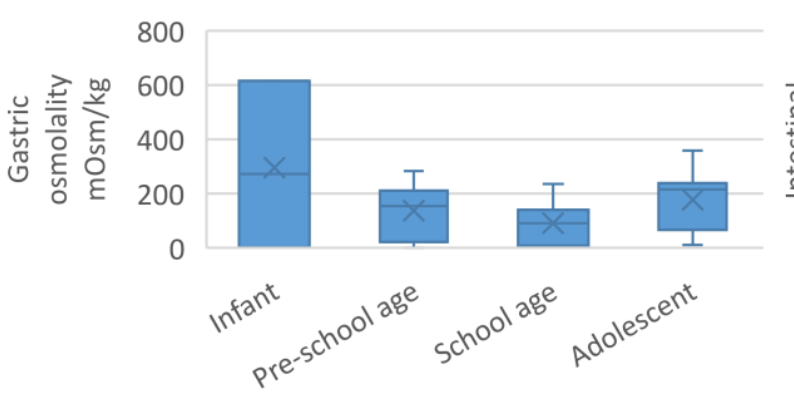

Age category (b)

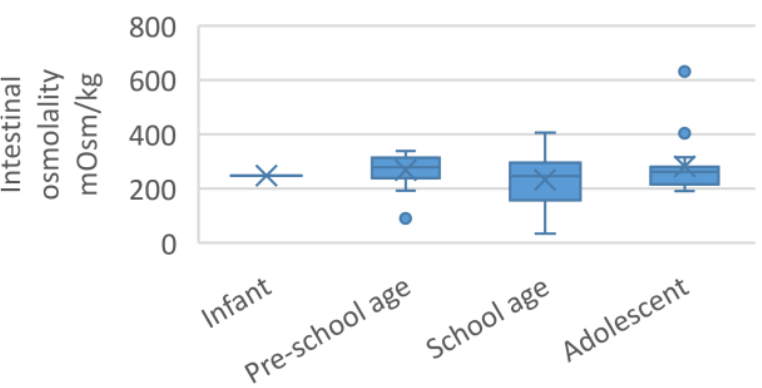

Age category 
Figure 3. Box and whisker plots showing the osmolality for (a) gastric and (b) intestinal samples by age group. Boxplots show mean as the $\mathrm{x}$; median as the horizontal line; box as the $1 Q$ and $3 Q$ and the whiskers are the range excluding outliers; outliers are shown as circles

The data generated in this study showed that gastric fluid osmolality values ranged from 1 to 615 $\mathrm{mOsm} / \mathrm{kg}$, while intestinal fluid values ranged from 35 to $631 \mathrm{mOsm} / \mathrm{kg}$. Outliers, as identified in Figure 3 were excluded prior to statistical analysis and the median, mean and standard deviation for each age group are shown in Table 6 . Statistically significant differences were observed between the gastric osmolality in infants compared to that in school age children, however the variability was large for infants and the sample size small thus caution is required with the interpretation of this data.

\begin{tabular}{|c|c|c|c|c|c|}
\hline & & Infants & $\begin{array}{c}\text { Pre-school } \\
\text { Children }\end{array}$ & $\begin{array}{l}\text { School age } \\
\text { children }\end{array}$ & Adolescents \\
\hline \multirow{4}{*}{ 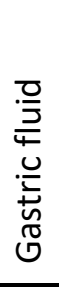 } & $\begin{array}{l}\text { Number of } \\
\text { samples }\end{array}$ & 3 & 16 & 14 & 20 \\
\hline & Median & 272.00 & 154.50 & 91.00 & 216.00 \\
\hline & Mean & 296.33 & 137.50 & 91.79 & 176.75 \\
\hline & $\begin{array}{l}\text { Standard } \\
\text { deviation }\end{array}$ & 307.22 & 96.65 & 71.79 & 100.87 \\
\hline \multirow{4}{*}{ 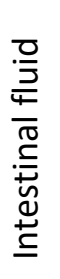 } & $\begin{array}{l}\text { Number of } \\
\text { samples }\end{array}$ & 2 & 15 & 5 & 14 \\
\hline & Median & - & 283.00 & 246.00 & 260.50 \\
\hline & Mean & 248.00 & 280.47 & 237.60 & 248.29 \\
\hline & $\begin{array}{l}\text { Standard } \\
\text { deviation }\end{array}$ & - & 42.24 & 51.22 & 36.58 \\
\hline
\end{tabular}

Table 6. Median, mean and standard deviation of the osmolality of gastric and intestinal samples. Note that outliers were excluded from this analysis.

There is limited data available on osmolality in paediatric populations. Previous reports from aspirated gastric fluids from children include mean values of $253 \mathrm{mOsm} / \mathrm{L}$ from a sample of 40 children under 2 years of age [49] and median values of $274 \mathrm{mOsm} / \mathrm{kg}$ for neonates; $188 \mathrm{mOsm} / \mathrm{kg}$ for children aged 212 years and $219 \mathrm{mOsm} / \mathrm{kg}$ for adolescents (12-18 years) [15]. Note that some studies reported osmolarity (per litre) whereas others report osmolality (per $\mathrm{kg}$ ), these units can be interchanged if we assume that the density of the carrier fluid is $1 \mathrm{~kg} / \mathrm{L}$. Thus the data obtained in our study shows relatively low values for gastric osmolality in comparison with previous studies. The presence of food components or digested food is likely to have a major effect on the osmolality of gastric fluids and is acknowledged as a potential limitation by other similar studies [15], our samples were from fasted patients which may explain our lower values.

Published data on osmolality of intestinal fluids in children was not identified, however, previous literature has reported osmolality values of $137-299 \mathrm{mOsm} / \mathrm{kg}$ in aspirated intestinal fluid from adults [30]. Thus, the osmolality values measured within this study are within the range previously reported for adults.

The osmolality of the current paediatric fasted state simulated gastric fluid proposed by [25] is 120.7 $\mathrm{mOsm} / \mathrm{kg}$ and our mean data (stratified by age) ranges from $91-216 \mathrm{mOsm} / \mathrm{kg}$ which encompasses 
this value. However, paediatric fasted state simulated intestinal fluid has an osmolality of 180 $\mathrm{mOsm} / \mathrm{kg}$ which is somewhat lower than the values measured in our study [25].

\section{Quantification of bile acids}

Bile acid concentrations were determined from 47 samples; both gastric and intestinal samples were bile acids from gastric and intestinal fluids by age $c$ summary data shown in Table 7.
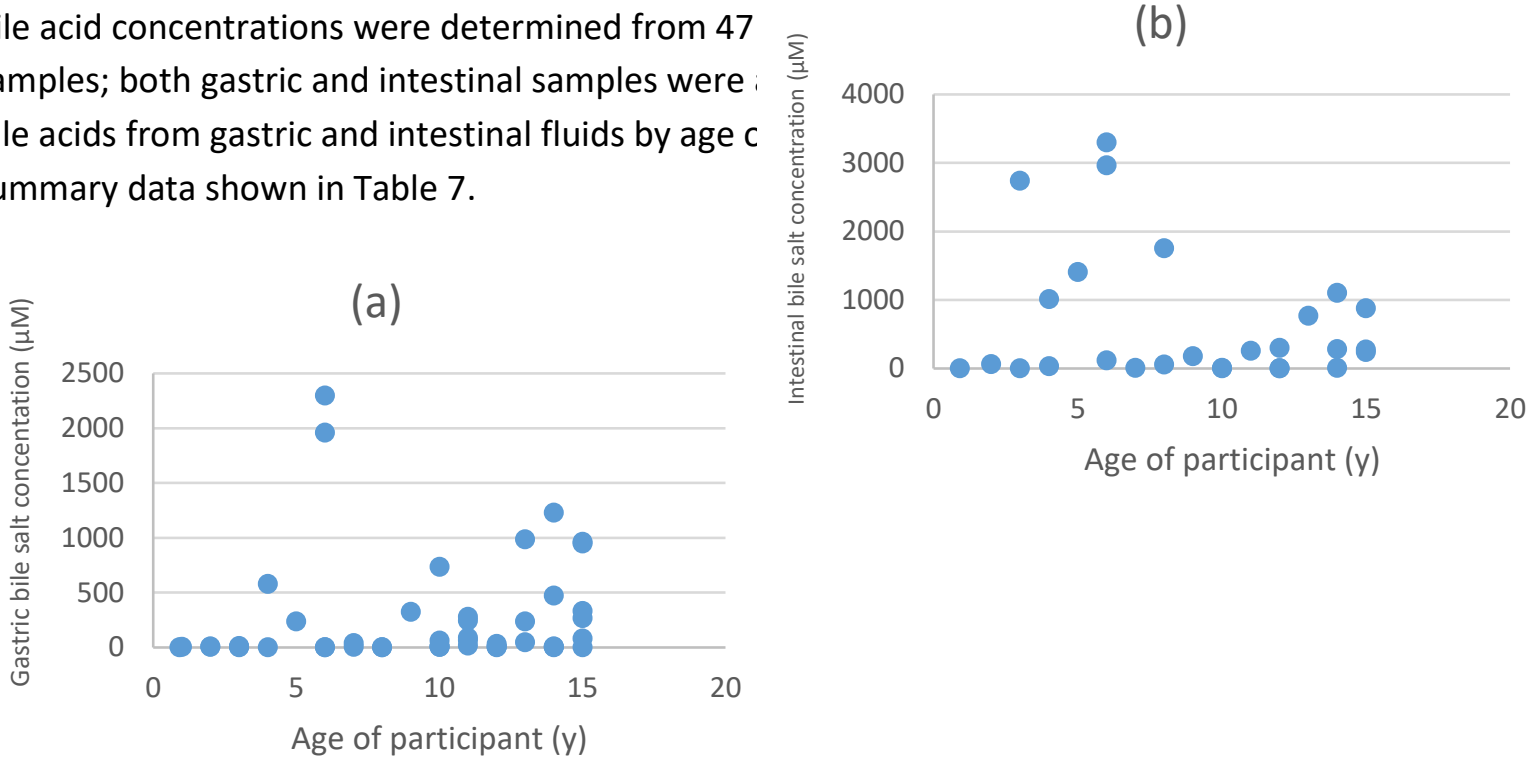

Figure 4. Total bile salt concentration $(\mu \mathrm{M})$ plotted versus the age of the participant in the (a) gastric and (b) intestinal fluids.

A summary table of the median; mean and standard deviation of the bile salt concentrations stratified by age is shown in Table 7.

\begin{tabular}{|c|c|c|c|c|c|}
\hline & & Infants & $\begin{array}{c}\text { Pre-school } \\
\text { Children }\end{array}$ & $\begin{array}{c}\text { School age } \\
\text { children }\end{array}$ & Adolescents \\
\hline \multirow{4}{*}{ 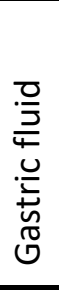 } & $\begin{array}{l}\text { Number of } \\
\text { samples }\end{array}$ & 2 & 8 & 19 & 18 \\
\hline & Median & - & 9.59 & 40.23 & 65.69 \\
\hline & Mean & 4.65 & 108.25 & 325.24 & 314.11 \\
\hline & $\begin{array}{l}\text { Standard } \\
\text { deviation }\end{array}$ & 2.07 & 207.66 & 663.87 & 420.76 \\
\hline \multirow{4}{*}{ 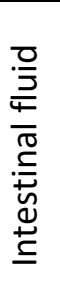 } & $\begin{array}{l}\text { Number of } \\
\text { samples }\end{array}$ & 1 & 6 & 10 & 10 \\
\hline & Median & 0.81 & 537.37 & 149.80 & 277.34 \\
\hline & Mean & 0.81 & 876.81 & 866.18 & 386.26 \\
\hline & $\begin{array}{l}\text { Standard } \\
\text { deviation }\end{array}$ & - & 1088.88 & 1308.14 & 393.84 \\
\hline
\end{tabular}

Table 7. Median, mean and standard deviation of the bile salt concentration $(\mu \mathrm{M})$ of gastric and intestinal samples.

The quantitative analysis of bile salts in both gastric and duodenal fluids (Figure 4) showed large variability among subjects and the summary of median, mean and standard deviation are presented in Table 7. The outliers were not excluded in this analysis as the variability as well as mean data is of interest for this population. These variabilities could be due to the presence of solid remnants in 
aspirated fluids. Some of the gastric samples collected were found to be transparent fluid and some contained suspended greenish floccules. It was observed that typically transparent fluids showed lower bile acid concentrations although this was not statistically significant. The total concentration of bile acids in gastric fluid ranged from 0.002-2.3 mM and in intestinal fluid from 0.0008-3.3 mM. These ranges are similar for those previously reported where large variability was also reported (see data in Table 1). However, the mean values are much lower than values in previous studies where mean values were typically greater than $2 \mathrm{mM}$ (see data and references from Table 1). This lower mean value may have implications for the solubilising capacity in paediatric populations as the critical micelle concentration for bile is often reported to be greater than $2 \mathrm{mM}$ [50].

There was no statistically significant differences in the bile acid concentrations with the age of the participants although there was a trend towards an increased mean concentration in the gastric fluid with increasing age. The large variability and small age-stratified sample sizes from intestinal fluids limit the interpretation of the data. Higher mean and median bile acid concentrations were found in the intestinal samples compared to the gastric samples. However, as stated previously there may be some mixing of these fluids during the endoscopy thus it was not appropriate to pool samples from the same individual.

The concentration of bile is typically lower in the stomach compared to the small intestine, as reflected in the concentration of bile salts in FaSSGF at $0.08 \mathrm{mM}$ whilst the concentration in FaSSIF is $3 \mathrm{mM}$ [48]. Proposed paediatric fasted state simulated gastric fluids reported a bile salt concentration of $0.02 \mathrm{mM}$ for neonates and $0.06 \mathrm{mM}$ for infants which is higher than that reported in our work yet still lower than that in adults which is supported by our data [25]. Due to the large variability in reported data two bile salt concentrations were proposed for paediatric FaSSIF to account for a minimum and maximum. These were $1.5 \mathrm{mM}$ and $4.5 \mathrm{mM}$ [25]. However, the bile acid concentrations measured in intestinal fluid in this study are lower and $<1 \mathrm{mM}$ in the majority of samples.

The relative contribution of individual bile acids to the total bile concentration was determined and the data are shown by individual sample in ascending order of age in Figure 5 . No trends were identified that linked bile acid concentration to age, thus the data were pooled for gastric and intestinal samples to determine the median, mean and standard deviation of each component identified, the data are presented in Table 8. 

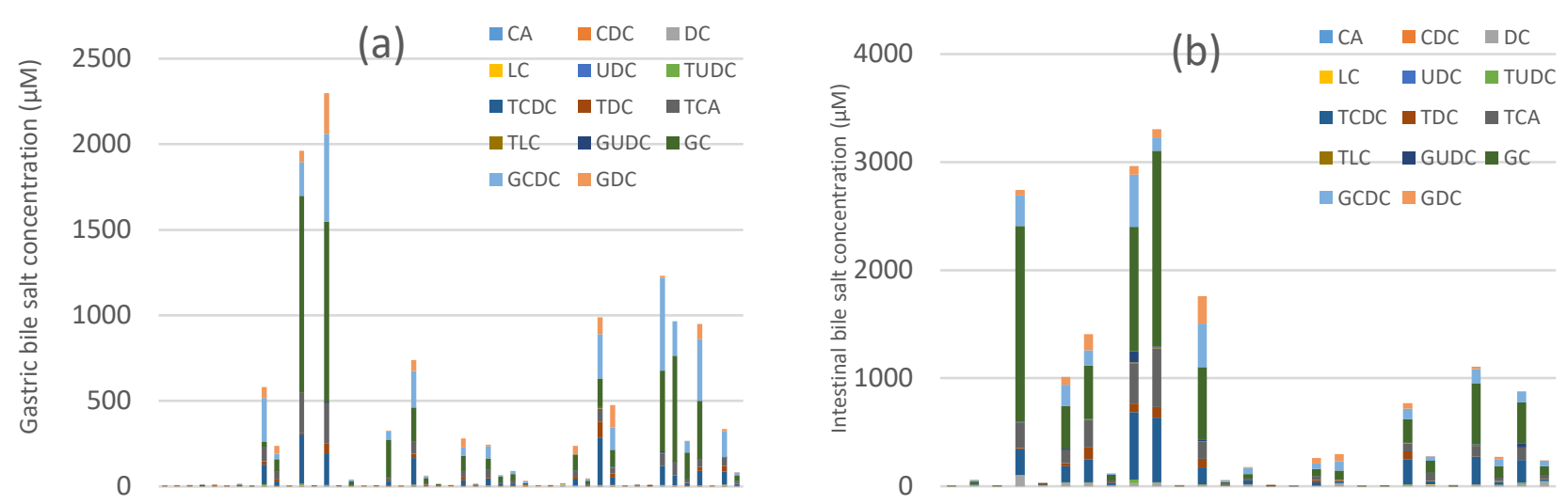

Figure 5. Relative contribution of bile salts to the total bile salt concentration in (a) gastric and (b) intestinal individual samples ordered from youngest to oldest within each population. 


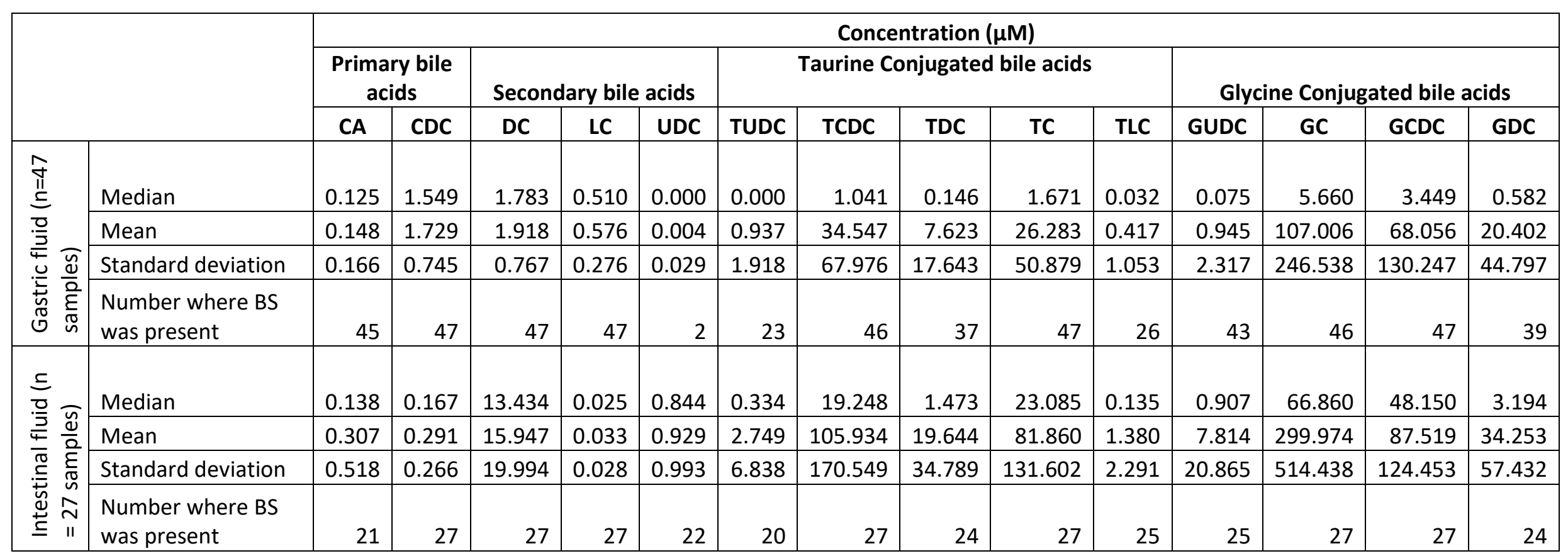

Table 8. Median, mean and standard deviation of the concentrations $(\mu \mathrm{M})$ of bile acids present in the gastric or intestinal fluid samples from children. 
In both gastric and intestinal fluids the most abundant bile acids were glycine conjugated with glycocholate being the most abundant. Primary bile acids were detected in almost all gastric samples as well as glycine conjugated bile acids. UDC was only present in 2/47 gastric fluid samples and TUDC and TLC were present in approximately half of the gastric samples. The order of magnitude (based on mean values) for the presence of bile acids in gastric fluid was GC> GCDC> $T C D C>T C>G D C>T D C>D C>C D C>$ GUDC $>$ TUDC $>$ LC $>T L C>C A>U D C$. This relative order matches well to the order previously reported by Riethorst et al (2016) based on adult gastric fluids [12]. There are some differences with the relative order reported by Van den Abeele et al (2018) yet this may be due to the difference in the ages within the paediatric populations or due to some contamination of gastric samples with intestinal fluids due to the method of sample collection [15].

Most bile acids were detected in the 27 intestinal fluid samples analysed. The taurine conjugated bile acids were present in higher levels compared to within the gastric samples. The order of magnitude (based on mean values) for the presence of bile acids in intestinal fluid was GC> TCDC> $\mathrm{GCDC}>\mathrm{TC}>\mathrm{GDC}>\mathrm{TDC}>\mathrm{DC}>\mathrm{GUDC}>\mathrm{TUDC}>\mathrm{UDC}>\mathrm{CA}>\mathrm{CDC}>\mathrm{LC}$. Previous literature (highlighted in Table 1) showed similarities to the relative concentrations found in these samples where GC; TC; GCDC and TCDC are the most commonly identified bile acids in paediatric intestinal fluids.

Further work is required to generate understanding on the implications of the range of bile salts present and their relative concentrations on the solubilisation of APIs. Specific work will investigate the impact of bile salt concentration and composition identified within this study on the solubility of a series of drugs previously investigated in adult human intestinal fluids $[8,51]$ to better understand how solubility may differ in a paediatric population compared to an adult population. Furthermore, the data will be used to drive the development of paediatric relevant fasted state simulated intestinal fluid to integrate into paediatric biopharmaceutics toolkits.

\section{General Discussion}

The data generated from the paediatric gastro-intestinal samples showed large inter-individual variability in all parameters characterised. There were no trends identified when the data was interrogated based on the age, ethnicity or disease-state of the participant. The lack of trends identified may have been masked by the variability observed. The similarities in the properties of the gastric and intestinal fluids suggests mixing of these fluids during the endoscopy procedure as this was conducted under anaesthetic. Characterisation from indwelling naso-gastric or naso-duodenal tubes would provide a cleaner data set and will be the target for future research.

However, the variability associated with gastro-intestinal fluids needs is an important finding as this can affect the solubility of drugs within a population. For example, recent work has highlighted that variability in bile acid metabolism as a result of gut microbiota can affect the solubility of a series of drugs [52]. Thus, it is prudent to develop a suite of biorelevant media for a paediatric population to

reflect this diversity and better understand the potential variability associated with solubility in vivo based on differences in the gastro-intestinal environment. The use of the median data to develop a mid-point fluid will provide a single point estimate for solubility whereas this in conjunction with extreme variants will provide understanding on the potential sensitivity to solubility within a highly variable paediatric population.

\section{Conclusions}


This work provides a comprehensive characterisation of gastric and intestinal fluids from a paediatric population. This provides a useful data set to generate simulated media to represent paediatric populations and to compare to existing simulated fluids based on adult data. The differences noted between paediatric and adult fluids justifies the need for additional experimental research to better understand the implications of these differences on drug solubility. It should be noted that there was large variability within the samples and that there was likely to be mixing of gastric and intestinal fluids. Caution is required for interpretation of the data as the mean values do not represent any single individual, therefore media that represent the extreme individual samples as well as the mean are likely to provide greater insights into the impact of fluid attributes on API solubility and dissolution in paediatric populations.

\section{Acknowledgements}

The authors would like to acknowledge all clinical staff involved in the study for their efforts in enrolling patients and collecting samples leading to the generation of the dataset.

Funding: This work was supported by Janssen Research and Development, Belgium. 


\section{Supplementary Information}

Supplementary Table 1. Summary of cohort details from studies reported where fasted gastrointestinal fluid was collected for characterisation

\begin{tabular}{|c|c|c|c|c|}
\hline Reference & Population & Fluids characterised & $\begin{array}{l}\text { Relevant } \quad \text { parameters } \\
\text { measured }\end{array}$ & Co-administration of water \\
\hline [4] & $\begin{array}{l}24 \text { adult healthy volunteers } \\
\text { (19-37 years) }\end{array}$ & $\begin{array}{l}\text { Fasted gastric and } \\
\text { jejunal fluid }\end{array}$ & $\begin{array}{l}\text { Bile salt content, } \mathrm{pH}, \\
\text { osmolality }\end{array}$ & None \\
\hline [5] & $\begin{array}{l}9 \text { healthy volunteers (age } \\
\text { not reported) }\end{array}$ & Fasted jejunal fluid & $\begin{array}{l}\text { Bile salt content, } \mathrm{pH}, \\
\text { osmolality }\end{array}$ & None \\
\hline [6] & $\begin{array}{l}12 \text { healthy volunteers aged } \\
24-40\end{array}$ & Fasted jejunum & $\begin{array}{l}\text { Bile salt content, } \mathrm{pH} \text {, buffer } \\
\text { capacity }\end{array}$ & None \\
\hline [9] & $\begin{array}{l}6 \text { adult volunteers }(22-35 \\
\text { years) }\end{array}$ & $\begin{array}{l}\text { Fasted duodenal and } \\
\text { jejunal fluid }\end{array}$ & $\begin{array}{l}\text { Bile salt content, } \mathrm{pH}, \\
\text { osmolality, buffer capacity }\end{array}$ & None \\
\hline [7] & 5 adult healthy volunteers & Fasted duodenal fluid & $\begin{array}{l}\text { Bile salt content, } \mathrm{pH}, \\
\text { osmolality }\end{array}$ & None \\
\hline [8] & $\begin{array}{l}5 \text { healthy volunteers (24-39 } \\
\text { years) }\end{array}$ & Fasted duodenal fluid & $\begin{array}{l}\text { Bile salt content, pH, } \\
\text { osmolality }\end{array}$ & $\begin{array}{ll}\text { Sampling followed } 15 \\
\text { minutes post ingestion of } \\
250 \mathrm{~mL} \text { water }\end{array}$ \\
\hline [11] & $\begin{array}{l}4 \text { healthy volunteers (19-35 } \\
\text { years) }\end{array}$ & Fasted duodenal fluid & $\begin{array}{l}\text { Bile salt content, } \mathrm{pH}, \\
\text { osmolality, viscosity }\end{array}$ & $\begin{array}{l}\text { Sampling followed ingestion } \\
\text { of } 200 \mathrm{~mL} \text { water }\end{array}$ \\
\hline [10] & $\begin{array}{l}\text { Adult patients undergoing } \\
\text { thoracic surgery }\end{array}$ & Fasted gastric fluid & Bile salt content & None \\
\hline [12] & $\begin{array}{l}20 \text { adult healthy volunteers } \\
\text { (18-31 years) }\end{array}$ & Fasted duodenal fluid & Bile salt content, $\mathrm{pH}$ & $\begin{array}{l}250 \mathrm{~mL} \text { water administered } \\
\text { prior to sampling }\end{array}$ \\
\hline [15] & Paediatric ( $0-18$ years) & Fasted gastric fluid & $\begin{array}{l}\text { Bile salt content, } \mathrm{pH} \text {, } \\
\text { osmolality }\end{array}$ & None \\
\hline
\end{tabular}


Supplementary Table 2. Structure and properties of the bile acid standard used in the analysis.

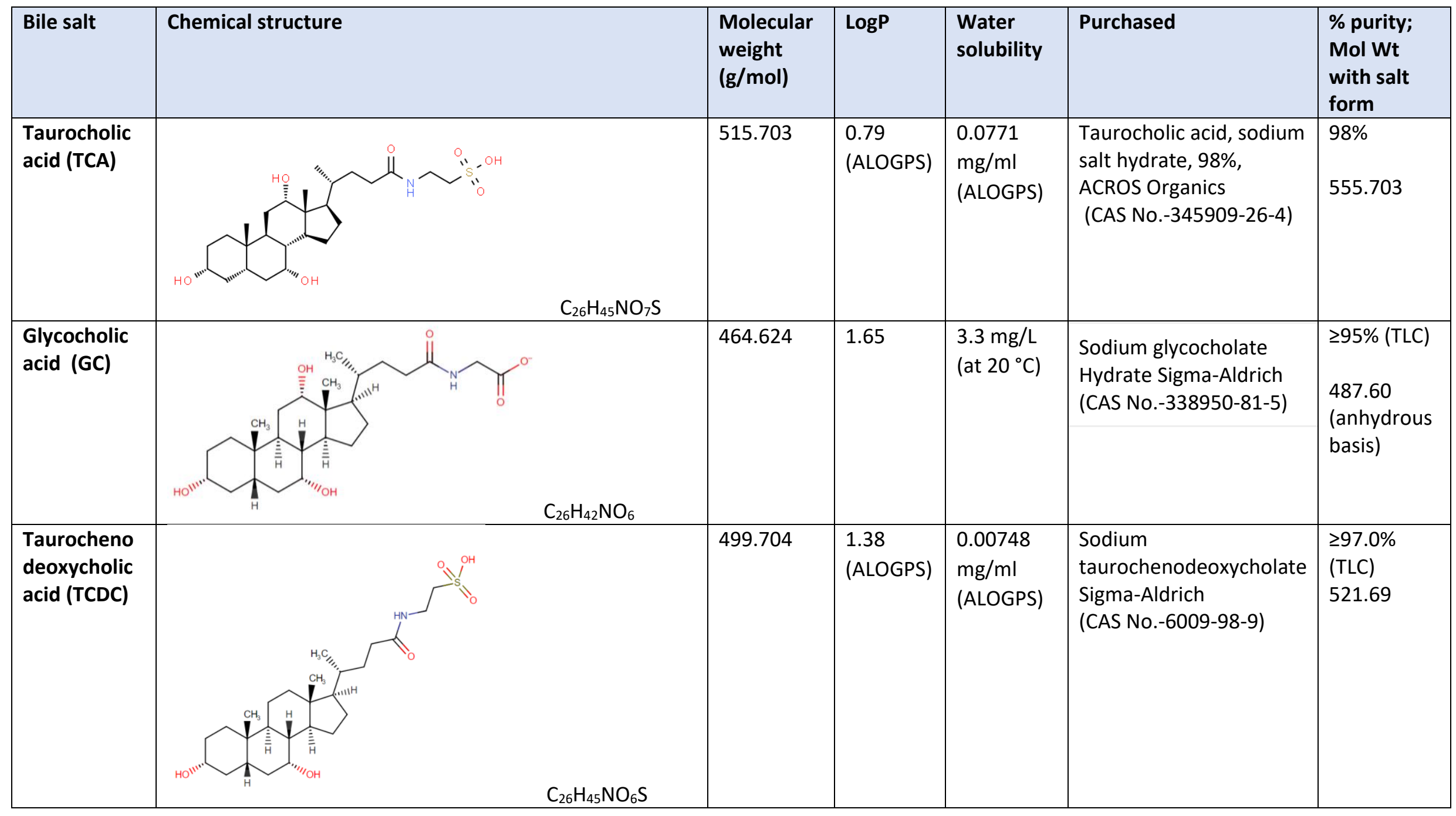




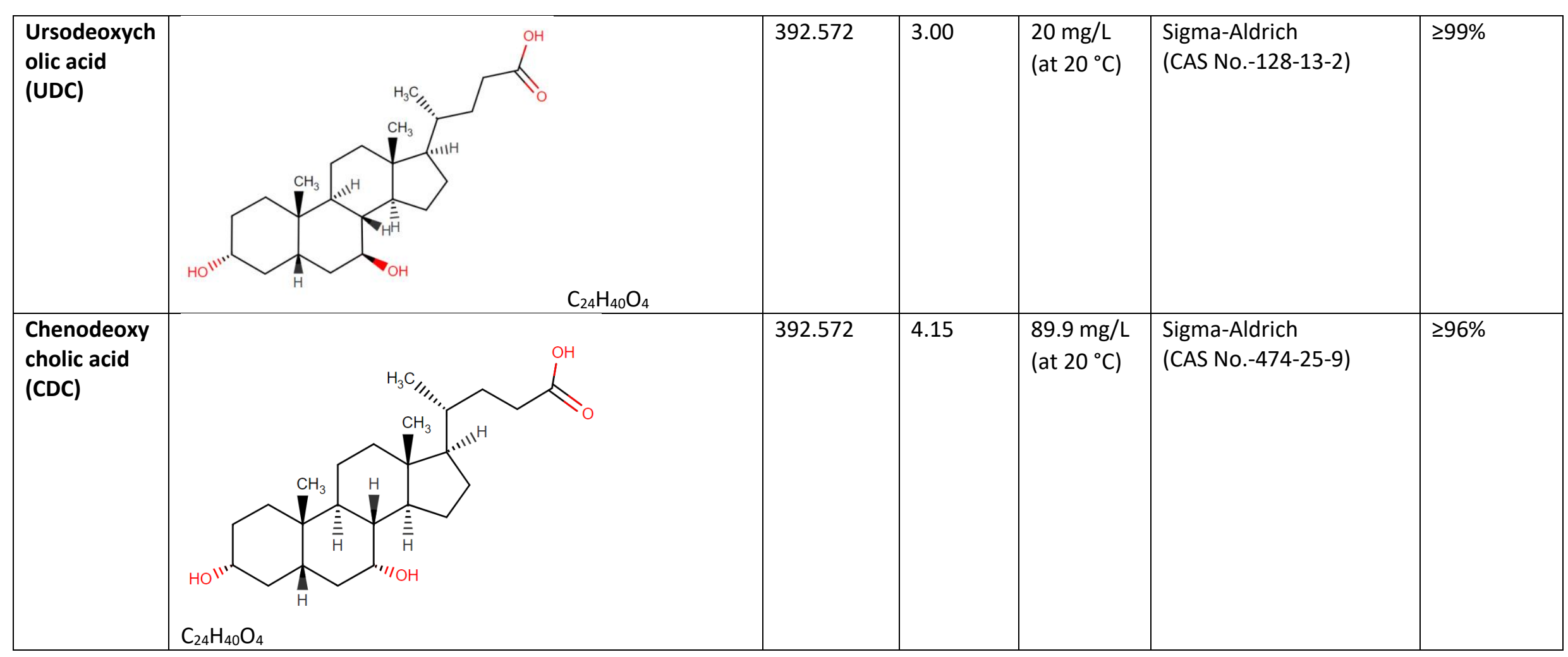




\begin{tabular}{|c|c|c|c|c|c|c|}
\hline $\begin{array}{l}\text { Deoxycholic } \\
\text { acid (DC) }\end{array}$ & (1) & 392.572 & 3.50 & $\begin{array}{l}43.6 \mathrm{mg} / \mathrm{L} \\
\text { (at } 20^{\circ} \mathrm{C} \text { ) }\end{array}$ & $\begin{array}{l}\text { Sigma-Aldrich } \\
\text { (CAS No.-474-25-9) }\end{array}$ & $\geq 98 \%$ \\
\hline $\begin{array}{l}\text { Glycochenod } \\
\text { eoxycholic } \\
\text { acid (GCDC) }\end{array}$ & (1)" & 449.6233 & 2.12 & $\begin{array}{l}3.15 \mathrm{mg} / \mathrm{L} \\
\text { (at } 20^{\circ} \mathrm{C} \text { ) }\end{array}$ & $\begin{array}{l}\text { Sodium } \\
\text { glycochenodeoxycholate } \\
\text { Sigma-Aldrich } \\
\text { (CAS No.-16564-43-5) }\end{array}$ & $\begin{array}{l}\geq 97 \% \\
\text { (HPLC) } \\
471.61\end{array}$ \\
\hline
\end{tabular}




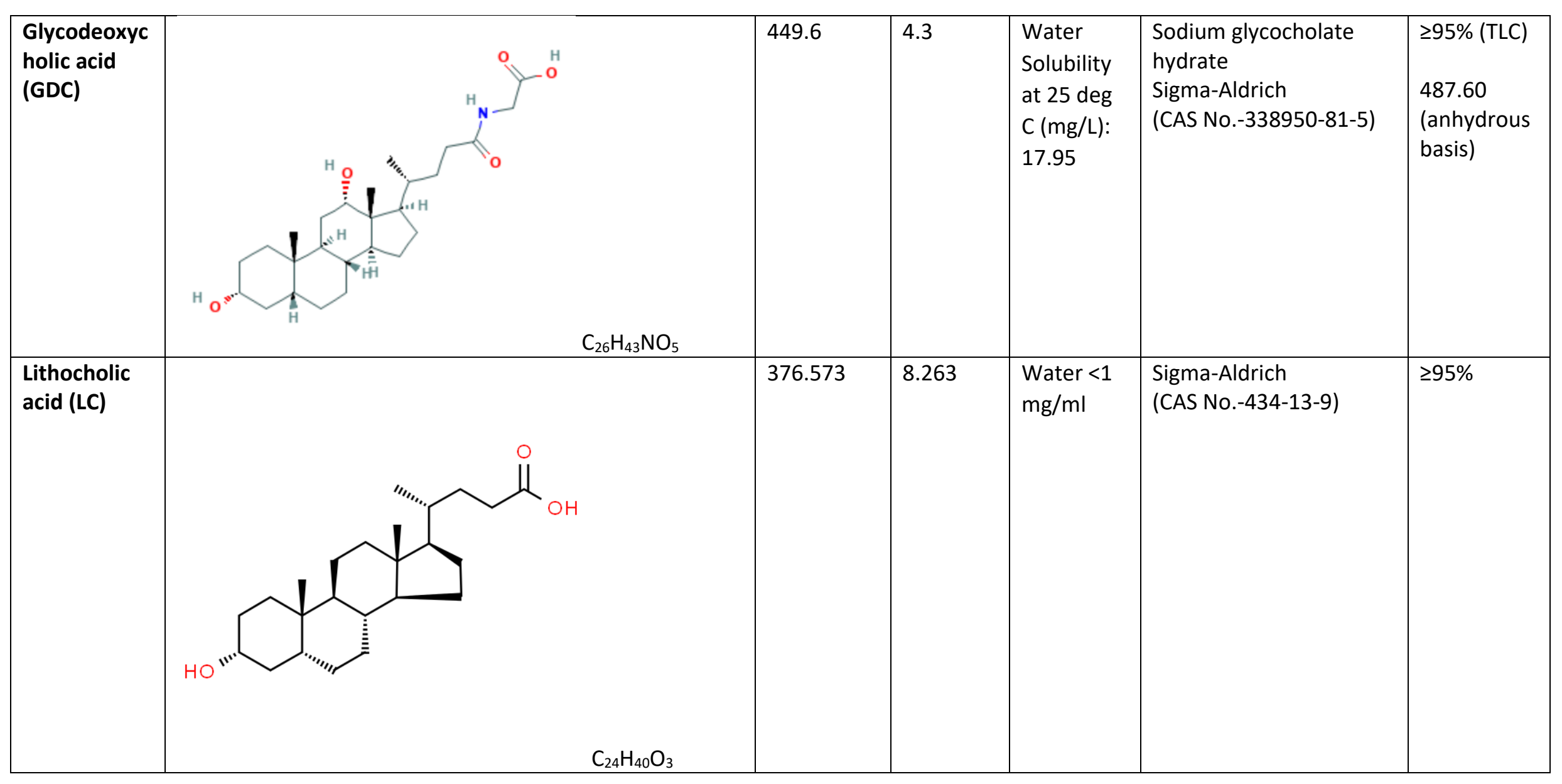




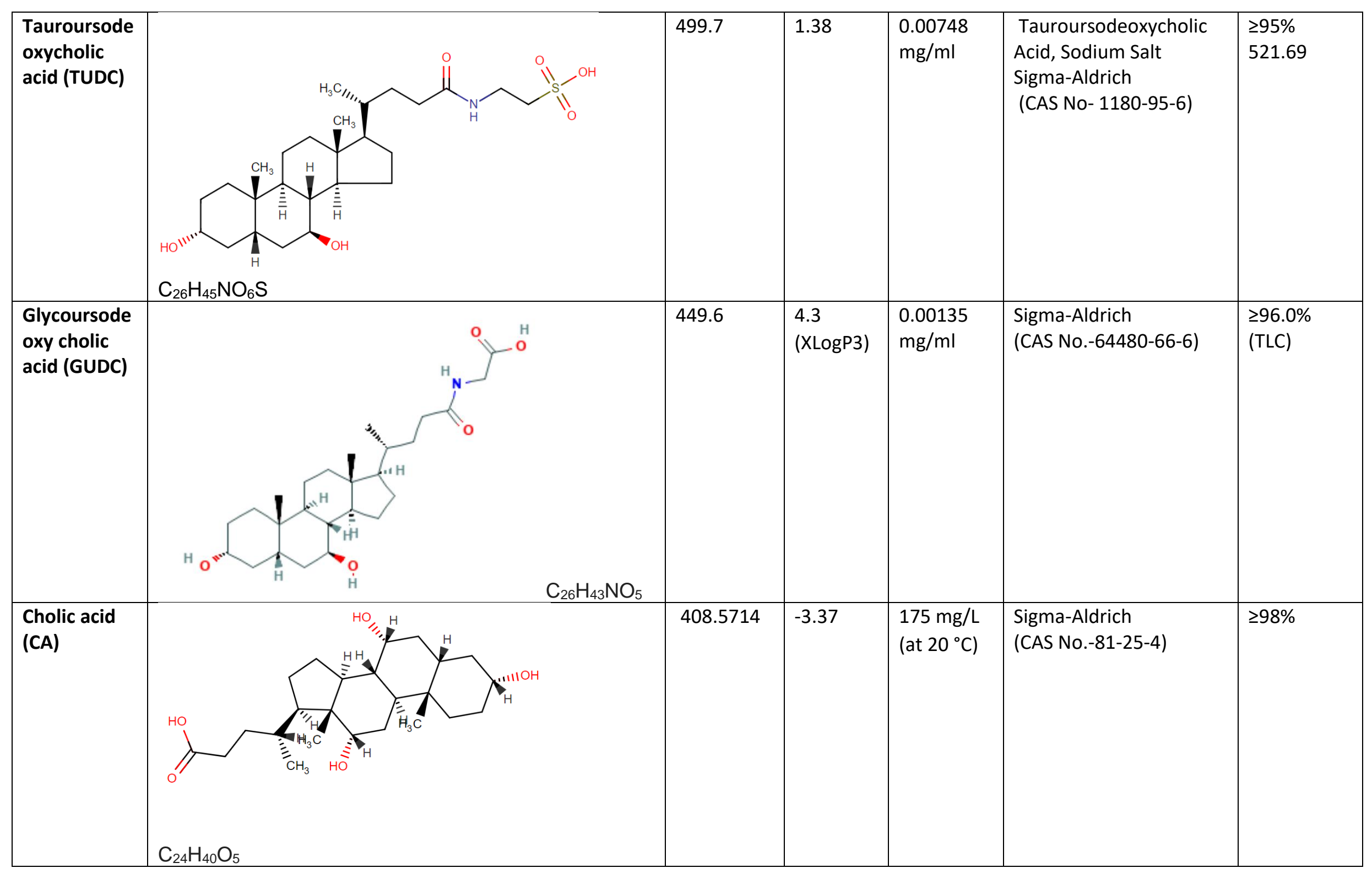




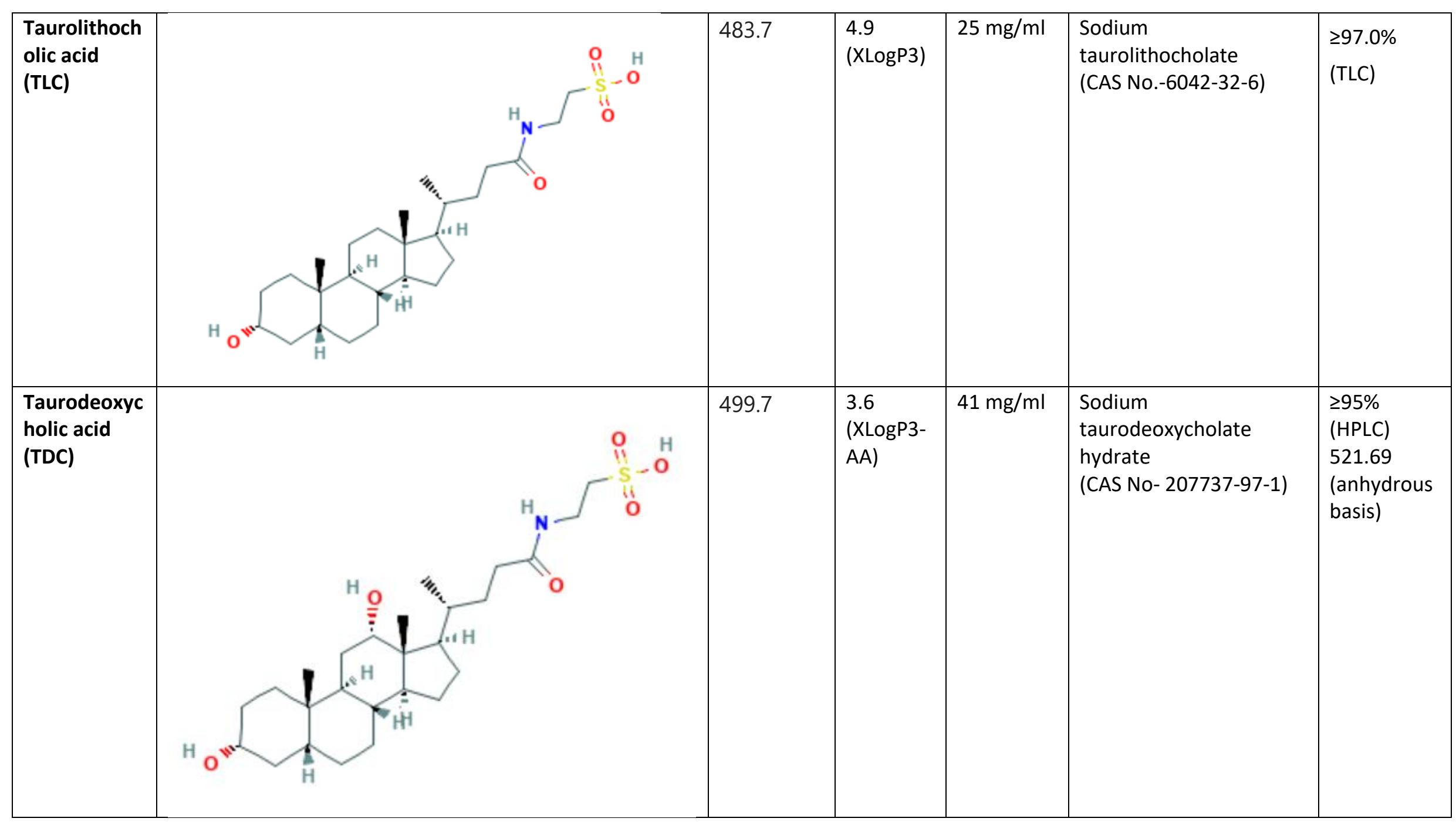




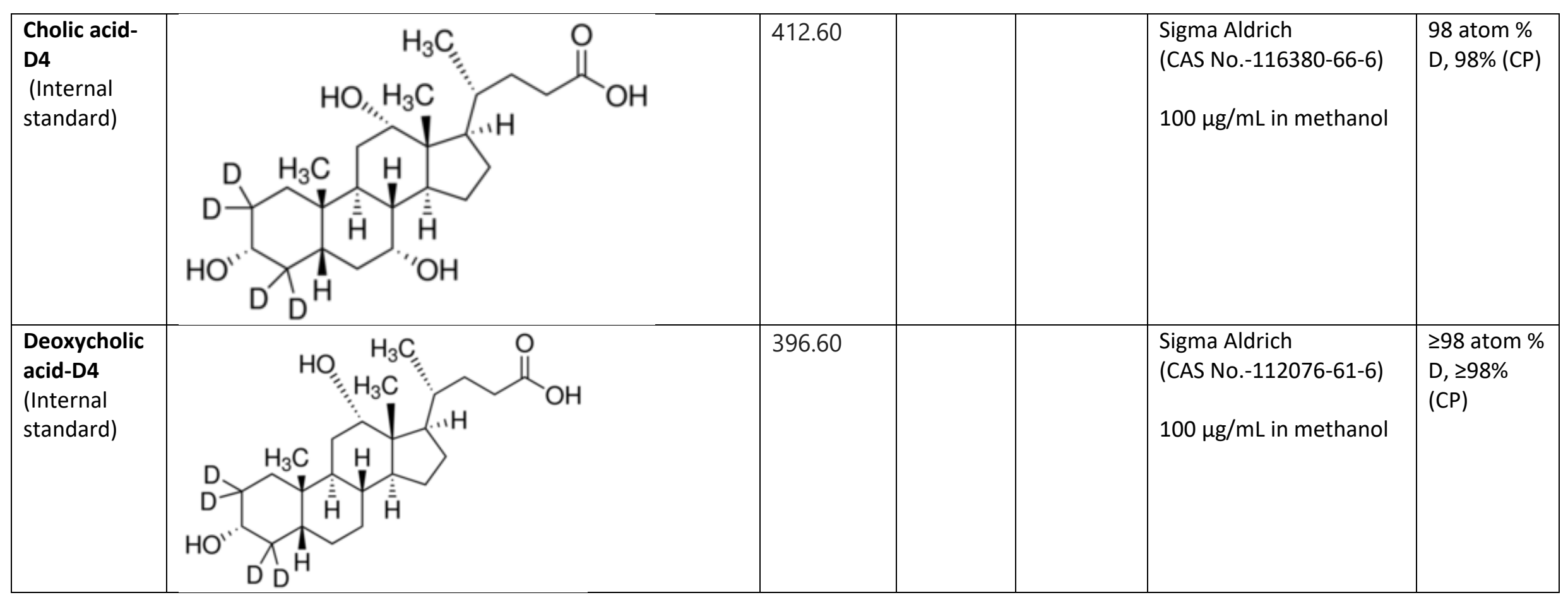


Table 3: Optimised MS/MS parameters for the analysis of bile acids

\section{Instrument- LC-MS/MS API 2000}

Method development: The parameters below in table were obtained using direct infusion experiments of the target compounds $(1000 \mathrm{ng} / \mu \mathrm{L}$ each, in $\mathrm{MeOH}: \mathrm{H} 20$ ) into the MS/MS system via a built-in Harvard syringe pump at a flow rate of $10 \mu \mathrm{L} / \mathrm{min}$

\begin{tabular}{|c|c|c|c|c|c|c|c|c|c|c|}
\hline & TCA & GC & TCDC & UDC & CDC & DC & GCDC & GDC & LC & D4C (IS-1) \\
\hline Ionization & Negative & Negative & Negative & Negative & Negative & Negative & Negative & Negative & Negative & Negative \\
\hline $\begin{array}{l}\text { Ion spray } \\
\text { voltage (V) }\end{array}$ & -4500 & -4500 & -4500 & -4500 & -4500 & -4500 & -4500 & -4500 & -4500 & -4500 \\
\hline $\begin{array}{l}\text { Curtain gas } \\
\text { (a.u.) }\end{array}$ & 35 & 35 & 35 & 35 & 35 & 35 & 35 & 35 & 35 & 35 \\
\hline $\begin{array}{l}\text { Temperatur } \\
\text { e }\left({ }^{\circ} \mathrm{C}\right)\end{array}$ & 275 & 275 & 275 & 275 & 275 & 275 & 275 & 275 & 275 & 275 \\
\hline $\begin{array}{l}\text { C.A.D gas } \\
\text { (a.u.) }\end{array}$ & 7.0 & 7.0 & 7.0 & 7.0 & 7.0 & 7.0 & 7.0 & 7.0 & 7.0 & 7.0 \\
\hline $\begin{array}{l}\text { Declustering } \\
\text { potential (V) }\end{array}$ & -70 & -50 & -50 & -55 & -40 & -50 & -50 & -50 & -40 & -50 \\
\hline $\begin{array}{l}\text { Focusing } \\
\text { potential (V) }\end{array}$ & -365 & -365 & -365 & -365 & -365 & -365 & -365 & -365 & -365 & -365 \\
\hline $\begin{array}{l}\text { Collision } \\
\text { energy (eV) }\end{array}$ & -110 & -70 & -120 & -20 & -20 & -30 & -70 & -70 & -30 & -30 \\
\hline $\begin{array}{l}\text { Cell } \\
\text { entrance } \\
\text { potential (V) }\end{array}$ & -10 & -10 & -10 & -10 & -10 & -10 & -10 & -10 & -10 & -10 \\
\hline $\begin{array}{l}\text { Cell exit } \\
\text { potential (V) }\end{array}$ & -6.0 & -6.0 & -6.0 & -6.0 & -6.0 & -4.0 & -6.0 & -6.0 & -6.0 & -6.0 \\
\hline $\begin{array}{l}\text { MRM } \rightarrow \text { Frag. } \\
\mathrm{m} / \mathrm{z}\end{array}$ & $\begin{array}{l}514.2 \rightarrow 8 \\
0\end{array}$ & $\begin{array}{l}464.3 \rightarrow 7 \\
4\end{array}$ & $\begin{array}{l}498.3 \rightarrow 8 \\
0\end{array}$ & $\begin{array}{l}391.3 \rightarrow 391 . \\
3\end{array}$ & $\begin{array}{l}391.3 \rightarrow 391 . \\
3\end{array}$ & $\begin{array}{l}391.3 \rightarrow 391 . \\
3\end{array}$ & $\begin{array}{l}448.3 \rightarrow 7 \\
4\end{array}$ & $\begin{array}{l}448.3 \rightarrow 7 \\
4\end{array}$ & $\begin{array}{l}375.3 \rightarrow 375 . \\
3\end{array}$ & $\begin{array}{l}411.2 \rightarrow 411 . \\
2\end{array}$ \\
\hline
\end{tabular}




\begin{tabular}{|c|c|c|c|c|c|c|}
\hline & TUDC & GUDC & CA & TLC & TDC & D4-DC \\
\hline Ionization & Negative & Negative & Negative & Negative & Negative & Negative \\
\hline Ion spray voltage (V) & -4500 & -4500 & -4500 & -4500 & -4500 & -4500 \\
\hline Curtain gas (a.u.) & 35 & 35 & 35 & 35 & 35 & 35 \\
\hline Temperature $\left({ }^{\circ} \mathrm{C}\right)$ & 275 & 275 & 275 & 275 & 275 & 275 \\
\hline C.A.D gas (a.u.) & 7.0 & 7.0 & 7.0 & 7.0 & 7.0 & 7.0 \\
\hline $\begin{array}{l}\text { Declustering } \\
\text { potential (V) }\end{array}$ & -50 & -50 & -50 & -50 & -40 & -50 \\
\hline $\begin{array}{l}\text { Focusing potential } \\
\text { (V) }\end{array}$ & -365 & -365 & -365 & -365 & -365 & -365 \\
\hline Collision energy (eV) & -110 & -70 & -30 & -108 & -116 & -30 \\
\hline $\begin{array}{l}\text { Cell entrance } \\
\text { potential (V) }\end{array}$ & -10 & -10 & -10 & -10 & -10 & -10 \\
\hline $\begin{array}{l}\text { Cell exit potential } \\
\text { (V) }\end{array}$ & -6.0 & -6.0 & -6.0 & -6.0 & -6.0 & -6.0 \\
\hline $\mathrm{MRM} \rightarrow$ Frag. $\mathrm{m} / \mathrm{z}$ & $498.3 \rightarrow 80.0$ & $448.3 \rightarrow 74$ & $407.3 \rightarrow 407.3$ & $482.2 \rightarrow 80.0$ & $498.3 \rightarrow 80.0$ & $395.3 \rightarrow 395.3$ \\
\hline
\end{tabular}

a.u. - arbitrary units; C.A.D - collisional activated dissociation; TC- Taurocholic acid; GC-Glycocholic acid; TCDC- Taurochenodeoxycholic acid; UDCUrsodeoxycholic acid; CDC- Chenodeoxycholic acid; DC- Deoxycholic acid; GCDC- Glycochenodeoxycholic acid; GDC- Glycodeoxycholic acid; LC- Lithocholic acid; D4C- Deuterated Cholic acid (Cholic-2,2,4,4-d4); TUDC- Tauroursodeoxycholic acid; GUDC-Glycoursodeoxy cholic acid; CA-Cholic acid; TLCTaurolithocholic acid; TDC- Taurodeoxycholic acid; D4-DC- Deuterated Deoxycholic acid; IS- Internal standard; MRM-Multi reaction monitoring; m/zmass/charge number 
1. Sun, D., et al., In vitro testing of drug absorption for drug 'developability' assessment: Forming an interface between in vitro preclinical data and clinical outcome. Current Opinion in Drug Discovery and Development, 2004. 7(1): p. 75-85.

2. Dressman, J.B., G.L. Amidon, and D. Fleisher, Absorption potential: estimating the fraction absorbed for orally administered compounds. J Pharm Sci, 1985. 74(5): p. 588-9.

3. Amidon, G.L., et al., A theoretical basis for a biopharmaceutic drug classification: the correlation of in vitro drug product dissolution and in vivo bioavailability. Pharm Res, 1995. 12(3): p. 413-20.

4. Lindahl, A., et al., Characterization of fluids from the stomach and proximal jejunum in men and women. Pharm Res, 1997. 14(4): p. 497-502.

5. Pedersen, B.L., et al., Dissolution of Hydrocortisone in Human and Simulated Intestinal Fluids. Pharmaceutical Research, 2000. 17(2): p. 183-189.

6. Persson, E.M., et al., The Effects of Food on the Dissolution of Poorly Soluble Drugs in Human and in Model Small Intestinal Fluids. Pharmaceutical Research, 2005. 22(12): p. 2141-2151.

7. Clarysse, S., et al., Postprandial Changes in Solubilizing Capacity of Human Intestinal Fluids for BCS Class II Drugs. Pharmaceutical Research, 2009. 26(6): p. 1456-1466.

8. Heikkilä, T., et al., Equilibrium drug solubility measurements in 96-well plates reveal similar drug solubilities in phosphate buffer $\mathrm{pH} 6.8$ and human intestinal fluid. International Journal of Pharmaceutics, 2011. 405(1): p. 132-136.

9. Perez de la Cruz Moreno, M., et al., Characterization of fasted-state human intestinal fluids collected from duodenum and jejunum. J Pharm Pharmacol, 2006. 58(8): p. 1079-89.

10. Foltz, E., et al., An assessment of human gastric fluid composition as a function of PPI usage. Physiological reports, 2015. 3(1): p. e12269.

11. Holmstock, N., et al., Exploring food effects on indinavir absorption with human intestinal fluids in the mouse intestine. European Journal of Pharmaceutical Sciences, 2013. 49(1): p. 27-32.

12. Riethorst, D., et al., Characterization of Human Duodenal Fluids in Fasted and Fed State Conditions. Journal of Pharmaceutical Sciences, 2016. 105(2): p. 673-681.

13. Pentafragka, C., et al., The impact of food intake on the luminal environment and performance of oral drug products with a view to in vitro and in silico simulations: a PEARRL review. Journal of Pharmacy and Pharmacology, 2019. 71(4): p. 557-580.

14. Vertzoni, M., et al., Luminal lipid phases after administration of a triglyceride solution of danazol in the fed state and their contribution to the flux of danazol across Caco-2 cell monolayers. Molecular pharmaceutics, 2012. 9(5): p. 1189-1198.

15. Van Den Abeele, J., et al., Gastric fluid composition in a paediatric population: Agedependent changes relevant for gastrointestinal drug disposition. European Journal of Pharmaceutical Sciences, 2018. 123: p. 301-311.

16. Litou, C., et al., Measuring pH and Buffer Capacity in Fluids Aspirated from the Fasted Upper Gastrointestinal Tract of Healthy Adults. Pharmaceutical Research, 2020. 37(3): p. 42.

17. Dressman, J.B. and C. Reppas, In vitro-in vivo correlations for lipophilic, poorly water-soluble drugs. European Journal of Pharmaceutical Sciences, 2000. 11: p. S73-S80.

18. Kleberg, K., J. Jacobsen, and A. Müllertz, Characterising the behaviour of poorly water soluble drugs in the intestine: application of biorelevant media for solubility, dissolution and transport studies. J Pharm Pharmacol, 2010. 62(11): p. 1656-68.

19. Batchelor, H.K., N. Fotaki, and S. Klein, Paediatric oral biopharmaceutics: Key considerations and current challenges. Advanced Drug Delivery Reviews, 2014. 73: p. 102-126. 
20. Batchelor, H., et al., Towards the development of a paediatric biopharmaceutics classification system: Results of a survey of experts. International Journal of Pharmaceutics, 2016. 511(2): p. 1151-1157.

21. del Moral Sanchez, J.M., et al., Biopharmaceutical optimization in neglected diseases for paediatric patients by applying the provisional paediatric biopharmaceutical classification system. British Journal of Clinical Pharmacology, 2018. 84(10): p. 2231-2241.

22. Delmoral-sanchez, J.M., et al., Classification of WHO essential oral medicines for children applying a provisional pediatric biopharmaceutics classification system. Pharmaceutics, 2019. 11(11).

23. Bhatt-Mehta, V., H. Hammoud, and G.L. Amidon, A proposed pediatric biopharmaceutical classification system for medications for chronic diseases in children. European Journal of Pharmaceutical Sciences, 2020. 152: p. 105437.

24. Papadatou-Soulou, E., et al., Magnetic Resonance Imaging Quantification of Gastrointestinal Liquid Volumes and Distribution in the Gastrointestinal Tract of Children. Molecular Pharmaceutics, 2019. 16(9): p. 3896-3903.

25. Maharaj, A.R., A.N. Edginton, and N. Fotaki, Assessment of Age-Related Changes in Pediatric Gastrointestinal Solubility. Pharmaceutical Research, 2016. 33(1): p. 52-71.

26. Mithani, S.D., et al., Estimation of the increase in solubility of drugs as a function of bile salt concentration. Pharm Res, 1996. 13(1): p. 163-7.

27. Madsen, C.M., et al., Effect of composition of simulated intestinal media on the solubility of poorly soluble compounds investigated by design of experiments. European Journal of Pharmaceutical Sciences, 2018. 111: p. 311-319.

28. Perrier, J., et al., Statistical investigation of the full concentration range of fasted and fed simulated intestinal fluid on the equilibrium solubility of oral drugs. European Journal of Pharmaceutical Sciences, 2018. 111: p. 247-256.

29. Hofmann, A.F., The Continuing Importance of Bile Acids in Liver and Intestinal Disease. Archives of Internal Medicine, 1999. 159(22): p. 2647-2658.

30. Fuchs, A. and J.B. Dressman, Composition and Physicochemical Properties of Fasted-State Human Duodenal and Jejunal Fluid: A Critical Evaluation of the Available Data. Journal of Pharmaceutical Sciences, 2014. 103(11): p. 3398-3411.

31. Reppas, C., et al., Characterization of Contents of Distal Ileum and Cecum to Which Drugs/Drug Products are Exposed During Bioavailability/Bioequivalence Studies in Healthy Adults. Pharmaceutical Research, 2015. 32(10): p. 3338-3349.

32. Norman, A., B. Strandvik, and Ö. Ojamae, Bile acids and pancreatic enzymes during absorption in the newborn. Acta Paediatrica, 1972. 61(5): p. 571-576.

33. Signer, E., et al., Role of bile salts in fat malabsorption of premature infants. Archives of disease in childhood, 1974. 49(3): p. 174-180.

34. Challacombe, D.N., S. Edkins, and G.A. Brown, Duodenal bile acids in infancy. Archives of disease in childhood, 1975. 50(11): p. 837-843.

35. Brueton, M.J., et al., Duodenal bile acid conjugation patterns and dietary sulphur amino acids in the newborn. Gut, 1978. 19(2): p. 95-8.

36. Glasgow, J.F., et al., A comprehensive study of duodenal bile salts in newborn infants and their relationship to fat absorption. Ir J Med Sci, 1980. 149(9): p. 346-56.

37. Jarvenpaa, A.L., Feeding the low-birth-weight infant. IV. Fat absorption as a function of diet and duodenal bile acids. Pediatrics, 1983. 72(5): p. 684-9.

38. Boehm, G., et al., Activities of lipase and trypsin in duodenal juice of infants small for gestational age. J Pediatr Gastroenterol Nutr, 1991. 12(3): p. 324-7.

39. Boehm, G., et al., Bile Acid Concentrations in Serum and Duodenal Aspirates of Healthy Preterm Infants: Effects of Gestational and Postnatal Age. Neonatology, 1997. 71(4): p. 207214. 
40. Szarszewski, A., et al., Duodenogastric reflux: clinical and therapeutic aspects. Archives of Disease in Childhood, 1999. 81(1): p. 16.

41. Fallingborg, J., et al., Measurement of gastrointestinal $\mathrm{pH}$ and regional transit times in normal children. Journal of Pediatric Gastroenterology and Nutrition, 1990. 11(2): p. 211214.

42. Schmidt, A.R., et al., Gastric $p H$ and residual volume after 1 and $2 \mathrm{~h}$ fasting time for clear fluids in children. British Journal of Anaesthesia, 2015. 114(3): p. 477-482.

43. Kalantzi, L., et al., Characterization of the Human Upper Gastrointestinal Contents Under Conditions Simulating Bioavailability/Bioequivalence Studies. Pharmaceutical Research, 2006. 23(1): p. 165-176.

44. Krafte-Jacobs, B., et al., Rapid placement of transpyloric feeding tubes: a comparison of $\mathrm{pH}$ assisted and standard insertion techniques in children. Pediatrics, 1996. 98(2 Pt 1): p. 242-8.

45. Gharpure, V., et al., Indicators of postpyloric feeding tube placement in children. Crit Care Med, 2000. 28(8): p. 2962-6.

46. Westhus, N., Methods to test feeding tube placement in children. MCN Am J Matern Child Nurs, 2004. 29(5): p. 282-7; quiz 290-1.

47. Metheny, N.A., et al., Clinical Research: Indicators of Feeding-Tube Placement in Neonates. Nutrition in Clinical Practice, 1999. 14(6): p. 307-314.

48. Jantratid, E., et al., Dissolution media simulating conditions in the proximal human gastrointestinal tract: an update. Pharm Res, 2008. 25(7): p. 1663-76.

49. Wakayama, Y., S. Wilkins, and K. Kimura, Is 5\% dextrose in water a proper choice for initial postoperative feeding in infants? Journal of Pediatric Surgery, 1988. 23(7): p. 644-646.

50. Subuddhi, U. and A.K. Mishra, Micellization of bile salts in aqueous medium: A fluorescence study. Colloids and Surfaces B: Biointerfaces, 2007. 57(1): p. 102-107.

51. de la Cruz-Moreno, M.P., et al., Exploring drug solubility in fasted human intestinal fluid aspirates: Impact of inter-individual variability, sampling site and dilution. Int J Pharm, 2017. 528(1-2): p. 471-484.

52. Enright, E.F., et al., Impact of Gut Microbiota-Mediated Bile Acid Metabolism on the Solubilization Capacity of Bile Salt Micelles and Drug Solubility. Molecular Pharmaceutics,

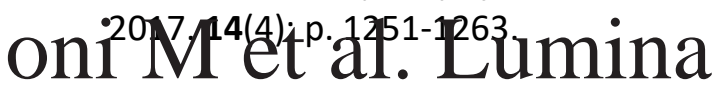

\section{1 lid}

